Department of Social Systems and Management

\author{
Discussion Paper Series
}

No.1274

Growth with Equity for the Development of

Mexico:Poverty, Inequality, and Economic

Growth(1992-2008)

by

Alberto J. INIGUEZ-MONTIEL

July 2011

UNIVERSITY OF TSUKUBA

Tsukuba, Ibaraki 305-8573 JAPAN 


\title{
GROWTH WITH EqUiTY FOR THE DEVELOPMENT OF MEXICO: POVERTY, INEQUALITY, AND ECONOMIC GROWTH (1992-2008) मे
}

\author{
Alberto J. Iniguez-Montiel \\ Graduate School of Systems and Information Engineering, \\ University of Tsukuba, 1-1-1 Tennodai, Tsukuba, Ibaraki, 305-8573 Japan. \\ E-mail: iniguez@sk.tsukuba.ac.jp \\ Tel.: +81-29-853-5175 / Fax: +81-29-853-5070
}

\begin{abstract}
How to decrease poverty has been extensively analyzed in the last two decades but, especially so, after the adoption of the millennium declaration (United Nations, 2000), which recognizes the elimination of poverty as one of the most important development goals. There are two important factors contributing to poverty reduction: economic growth and decrease in inequality. This paper constitutes an attempt to determine the relative contribution of changes in those variables to changes in poverty in Mexico by applying standard decomposition techniques and other methodologies that have been proposed to analyze the, sometimes, overlooked and underestimated impact of inequality on poverty. Our findings clearly indicate that growth with redistribution (lower income inequality) was indeed the key to reducing poverty continuously and in an important manner during 2000-2006. However, after 2006, decreasing per-capita income, and the persistently high inequality (Gini of $52 \%$ ) in the country, caused the reversal of the favorable trend observed since 1996, raising poverty to pre-2002 levels. It follows that, for Mexico, a middle-income country exhibiting quite low growth rates and high inequality levels, the further improvement in its distribution of income is essential if Mexico's $57 \%$ of the population (61 million people in 2008 ) is ever to be raised out of poverty. Consequently, the implementation of an active pro-poor growth policy should be strongly encouraged.
\end{abstract}

Keywords: Poverty; inequality; redistribution; pro-poor growth; Mexico; Latin America.

JEL Classification: D31, I32, O12, O54.

\footnotetext{
4 This paper is based on part of my doctoral dissertation. I am grateful to Yoko Kijima for her supreme supervision of my research. I also wish to thank Atsushi Yoshida, Kaori Miyazaki, Mari Minowa, Seki Asano, Stephen Turnbull and Takashi Kurosaki, as well as seminar audiences at the Bank of Mexico and the 2011 Japanese Economic Association conference, for helpful comments and suggestions. The financial support provided by the Bank of Mexico during my participation in its summer internship program, where I worked on the initial phase of this research, is gratefully acknowledged. Of course, any remaining errors are my own.
} 


\section{INTRODUCTION}

Poverty reduction is considered as one of the most important development goals for developing and developed countries alike (United Nations, 2000). Progress on the realization of this goal is perhaps what policy makers, especially in developing countries, have sought so badly to attain in the last decades, by promoting economic growth, implementing redistribution policies, or a combination of the two. However, the poverty outcomes have varied widely across countries depending on the particular success of their development strategies.

By focusing on the specific impact of inequality and growth on poverty, several studies have come to the conclusion that the distribution of income indeed matters for the poor ${ }^{1}$ (Datt and Ravallion (1992), Ravallion (1997, 2001, 2005), Deininger and Squire (1998), Ravallion and Chen (2003), Bourguignon (2004), Lopez (2006) among others) and that higher initial inequality tends to reduce the positive, reducing impact of growth on absolute poverty (Ravallion (1997, 2005), Lopez (2006), Lopez and Serven (2006)). In addition, it is now widely agreed that economic growth alone is not a sufficient condition for successfully achieving the goal of poverty reduction (Oxfam (2000), Addison and Cornia (2001), Ravallion and Datt (2002)). ${ }^{2}$

With respect to the relationship between inequality and poverty, there are two arguments as to why the level of inequality matters to subsequent rates of poverty reduction (Ravallion, 1997). The first, called the induced-growth

\footnotetext{
${ }^{1}$ For a long time, income inequality (distribution) has been neglected by policymakers and regarded more as a normal and unavoidable part of the economic process. However, according to the literature, the distribution of income is said to matter for the poor in the sense that it is a fundamental factor to be considered for reducing poverty since poverty reduction through growth is limited when income and assets inequality are high (Kakwani et al. (2000), Oxfam (2000), Addison \& Cornia (2001)). Accordingly, an improved distribution of income is found to have a double poverty-reducing effect; one that works directly via redistribution as lower-income households (people) are allowed to benefit more from the gains of growth, and another one that, by increasing economic growth, has a positive, indirect impact on the level of poverty via the "trickle down" (van der Hoeven, 2008).

${ }^{2}$ Economic growth is self-evidently good for poverty reduction, since without growth, the average incomes of the poor cannot rise over time, with attendant implications for poverty. But growth is not the only requirement. At any given level of average income, the incidence of poverty is determined by income distribution. The larger the share of any increment to growth captured by the poor, the faster the rate of poverty reduction (Oxfam, 2000).
} 
argument, has to do with the long-standing view that inequality is harmful for growth (Galor and Zeira (1993), Banerjee and Newman (1993), Alesina and Rodrik (1994), Benabou (1996), Deininger and Squire (1998), Ravallion and Datt (2002), Ravallion (2005), and Easterly (2007) among others) ${ }^{3}$ and, therefore, impedes progress in reducing absolute poverty. The second argument, or growth-elasticity one, states that even if the distribution of income is irrelevant to the rate of growth, it is important to assure that the distributional gains from growth are more proportionally shared by the poor and do not benefit mostly the rich (Ravallion, 2005, 2007). ${ }^{4}$

A few studies are found in the literature for the case of Mexico, analyzing the relationship between these variables. One of the pioneer papers in this field is the one of Szekely (1995), who, after finding out that the increase in poverty in 1984-1989 was mainly attributed to the sharp inequality rise after 1984 and carrying out some simulations, concluded that the improvements in the distribution of income were as important or even more important than growth for the increase in the well-being of the poor in Mexico. ${ }^{5}$ Another study by Cortes et al. (2002) analyzed poverty in 1992-2000, using the methodology proposed by Datt and Ravallion (1992). ${ }^{6}$ The authors came to the conclusion that, during 1992-1996 and 1996-2000, average income growth determined for the most part changes in the poverty level, while distributional changes were mainly unimportant at the national level but played an important role in the rural sector (significantly reducing poverty in 1992-1996, and increasing it considerably in 1996-2000).

The evolution of relative poverty in Mexico is said to have followed closely the

\footnotetext{
3 The traditional view stating that inequality is growth-enhancing and a normal part of the development process (Kuznets, 1955) was put into question and challenged by a number of empirical studies, which found a negative correlation between the average rate of growth and a number of inequality measures. For a review of the literature, the reader is referred to Aghion et al. (1999) and Thorbecke \& Charumilind (2002).

4 According to the literature, inequality hampers poverty reduction, not only because of its negative impact on the growth elasticity of poverty but also because of its negative impact on the inequality elasticity of poverty (Lopez (2006), Lopez \& Serven (2006)).

5 The poverty line of 30.37 dollars, considered in Szekely (1995), included the costs of the minimum necessary food, housing, health and education per month per head at September 1989 prices, which according to COPLAMAR (the governmental agency in charge of alleviating extreme poverty in Mexico from the late 1970s to the early 1980s) represented the value of the extreme poverty line in the country.

${ }^{6}$ The methodology proposed in Datt \& Ravallion (1992) is also applied in the present paper.
} 
economic cycle, at least, until the year 2000 (Cortes et al., 2002). However, during 2000-2006, this was no longer the case and, even though the economy was in recession in the early 2000s (2001-2003), poverty continued declining until 2006. Thus, it is important to examine rigorously the causes of this reduction in poverty after 2000, in order to determine whether the economic growth is still the major reason for that or the redistribution played an important role for decreasing poverty.

The present study extends further the poverty analysis for Mexico along the previous lines and attempts to identify the existent relationship between income inequality and poverty from 1992 to 2008 . We rely on the application of different decomposition techniques and other methodologies that have been proposed to analyze the, sometimes, overlooked and underestimated impact of inequality on poverty. By doing so, this study additionally allows us to assess the overall poverty alleviation/reduction strategy followed by the Mexican government in the last two decades.

Our main findings relate to the important role played by income inequality (redistribution) for poverty reduction in Mexico. ${ }^{7} \mathrm{We}$ could, therefore, corroborate that the high and persistent levels of income inequality that were present during the 1990s counteracted the positive impact of growth and prevented the further decline of poverty, especially in 1996-2000. Moreover, it was found that the improvement that took place along the distribution of income in Mexico after $2000,{ }^{8}$ contributed in an important manner to reducing poverty in 2000-2006 but was unable to offset the strong, poverty-augmenting effect of decreasing per-capita income in 2006-2008, which eventually led to the reversal of the favorable trend observed since the mid-1990s, raising poverty to pre-2002 levels.

\footnotetext{
7 This is consistent with Ravallion (2005), who explains that the initial level of inequality and inequality changes over time are the two main proximate causes of the differing total elasticities of poverty reduction.

8 The post-1990s improvement in the distribution of income in Mexico is associated to a relatively small inequality reduction of less than 3\% points in the Gini coefficient, from 54.64 to $52.03 \%$ in 2000 and 2002 respectively, which remained approximately constant thereafter, (Iniguez-Montiel, 2011) and a 25\% average growth rate in the incomes of the poor (households below the $40^{\text {th }}$ percentile of the income distribution), identified in this study (see Section 4, "Measuring Pro-poor Growth").
} 
Thus, we argue that the further decline of income inequality in Mexico through redistribution, along with the urgent economic development of the rural sector long-ago indicated in McKinley and Alarcon (1995), should be regarded as a top priority for policy makers if extreme and moderate poverty is ever to be eliminated. ${ }^{9}$ This points towards an inclusive development strategy that focuses on pro-poor growth as the main engine of Mexico's development and considers all sectors of the population, particularly the agricultural one, as equally important.

This paper is organized as follows. The next section provides a poverty profile of Mexico in 2008, comparing it to the one observed in 1992, and gives an account of the evolution of poverty, inequality and economic growth over the last decades. Section 3 explains the applied methodologies, while section 4 shows and discusses the results. Finally, section 5 concludes.

\section{Poverty, Inequality ANd Economic Growth in MeXico}

\section{DATA}

The information that will be used corresponds to the Household Income and Expenditure Survey (ENIGH) for the years 1992, 1994, 1996, 1998, 2000, 2002, 2004, 2006 and 2008. ENIGH is a nationally representative sample, covering both the rural and urban populations in the 32 Mexican states, conducted by the National Institute of Statistics, Geography and Informatics (INEGI). All the surveys were carried out during the same months of the year, using similar questionnaires and identical sampling techniques. Thus they are fully comparable between them. Additionally, it should be noted that the data is set in constant prices of July 2009, using the national consumer price index (CPI), ${ }^{10}$ in order to get comparable figures across time.

\section{Poverty MEAsuRes AND LiNES}

\footnotetext{
${ }^{9}$ According to Dagdeviren et al. (2004), redistribution is far more effective in reducing poverty than increases in economic growth that are distribution neutral. The authors concluded that redistribution of current income and assets, or redistribution of an economy's growth increment are the most effective forms of poverty reduction for most countries but, especially so, for middle-income ones (Dagdeviren et al., 2004).

${ }_{10}$ The CPI was obtained from the Bank of Mexico's web page at the following address: http://www.banxico.org.mx/politica-monetaria-e-inflacion/servicios/calculadora-inflacion.html
} 
The poverty measures and lines considered in this study are the following:

Poverty Measures:

- Headcount $(\mathrm{H})$ index: Proportion of households (people) that are considered poor in a society.

- Poverty-gap (PG) index: Proportion of total per-capita income that is necessary to raise the incomes of the poor to the poverty line.

- Foster-Greer-Thorbecke (FGT) index: This measure corresponds to the squared poverty-gap index proposed by Foster et al. (1984).

Poverty Lines: ${ }^{11}$

- Food Poverty: Official poverty line in Mexico that considers the minimum, monthly household per-capita income to satisfy food necessities.

- Capacities (Extreme) Poverty: Official poverty line in Mexico that considers the minimum, monthly household per-capita income to satisfy food, education and health necessities. It is related to extreme poverty and, consequently, to the Oportunidades program. ${ }^{12}$

- Basic-Needs Poverty: Official poverty line in Mexico that considers the minimum, monthly household per-capita income to satisfy food, education, health, clothing, housing and transportation necessities.

- Overall Poverty: Poverty line proposed by the Technical Committee for the Measurement of Poverty (CTMP, 2002) in Mexico, which considers additional basic necessities, to those included in the official basic-needs poverty line, that are essential to live in the modern Mexican society, like culture, recreation and retirement savings. It has been completely ignored from any policy debate and is not considered for the evaluation of poverty by the National Council for the Evaluation of Social Development Policy (CONEVAL) in Mexico.

- Moderate Poverty: Poverty condition that is suffered by those households

\footnotetext{
${ }^{11}$ It should be noted that all poverty lines, except the overall-poverty one, were obtained directly from the National Council for the Evaluation of Social Development Policy (CONEVAL) in Mexico. The rural and urban overall-poverty lines were calculated by using the inverse of the Engel coefficients of 2.2624 and 2.5, respectively, which are suggested in CTMP (2002).

${ }_{12}$ Oportunidades (formerly Progresa) is a conditional cash and in-kind transfer program of the federal government, aiming at the reduction and alleviation of extreme poverty in Mexico through the development of the human capital of poor households. It was launched in the year 1997 with a total beneficiary population of 300,000 households. Since the year 2004 , the program benefits about 5 million families, or 26 million people, in Mexico.
} 
(people) beyond extreme poverty in Mexico. It is obtained by subtracting extreme from overall poverty.

\section{MeXico's PoverTy PROfiLe}

This section provides a general overview of Mexico's poverty profile in order to appreciate the changes and/or improvements in the condition of the poor during the last two decades. We divide the analysis in two parts: I.) Economic Structure and II.) Within-group Poverty and Contribution to Poverty, each of them organized by education, occupation and location factors.

\section{ECONOMIC StRUCtURE}

\section{EDUCATION}

According to the World Bank (2007), there is a high level of education inequality in Mexico, where higher-income groups have substantially higher levels of education than the rest of the population. This situation, consequently, contributes to the high level of income inequality and limits the pool of skilled workers, ultimately limiting the potential of Mexico to compete with other knowledge-driven economies (World Bank, 2007). Without doubt, educational and income inequalities are one of the main factors responsible for the high levels of poverty in Mexico, working at the disadvantage for the poor. Table 1, showing the distribution of the population among the analyzed groups, corroborates the educational-inequality issue in Mexico, where only a minority (around $7.5 \%$ ) of household heads hold a university degree, while a large majority (more than $75 \%$ ) has an educational level equal or less than middle school. However, it is important to note that inequality of education has decreased considerably over time and, consequently, the proportion of head of households with no formal education declined by $15 \%$ points from 45.8 to $30.9 \%$ in 1992 and 2008. Additionally, it is possible to verify as well that the proportion of household heads with a level of education equal to middle and secondary school increased by 73 and $52 \%$, reaching 22.6 and $16.4 \%$ respectively in 2008 .

\section{OCCUPATION}

Traditionally, there are some occupations that are more related to poverty in Mexico than others. This is the case, for example, of agricultural and self-employed workers. As for the distribution of the population by occupation, it 
has not suffered dramatic changes in the last decades with the exception of a few categories. According to Table 1, the proportion of agricultural and industrial workers declined considerably in 1992-2008, especially that of the former group, whose population shrank by $32 \%$ from 18.6 to $12.6 \%$. In contrast, the inactive population, the self-employed workers and sellers, and the service workers increased their relative populations by 47,6 and $58 \%$ respectively within the period. As shown in the following subsection, these distributional changes determined to some extent the observed increase (reduction) in the contribution to poverty as the poor moved in (out) of these occupations.

\section{LOCATION}

Geographical location is another factor that is highly related to the condition of being poor in Mexico. ${ }^{13}$ According to our calculations (see Table 6), 47 and $32 \%$ of the rural sector were considered as extremely and moderately poor respectively in 2008 , which means that $79 \%$ of the total population in rural areas could not satisfy their basic necessities in some way or another. Contrastingly, only 12 and $28 \%$ of the urban population were regarded as extremely and moderately poor respectively in the same year. On the other hand, there are certain regions where poverty tends to be more acute as it is the case of the Southern and Central areas of the country. These patterns must definitely determine mobility within and between states, regions and sectors in Mexico.

As it is possible to see in Table 1, the distribution of the population by states remained practically unchanged in 1992-2008. There were only three main changes occurring in the states of Mexico and Quintana Roo, and the federal district, where the populations of the first two evidently increased, while that of the capital decreased by $1.5 \%$ points. Most probably, this situation reflects, in part, the mobility taking place between Mexico City and the state of Mexico (located next to each other) and other states, as people moves from the overly congested capital to medium-sized industrial cities in search for better opportunities and living conditions. ${ }^{14}$ Additionally, in the case of Quintana Roo,

\footnotetext{
${ }^{13}$ A majority of the world's poor are still located in the rural areas and this is likely to remain true for some time to come (Ravallion, 2002, 2005).

${ }_{14}$ According to Currit \& Easterling (2009), the adoption of the maquiladora model in Mexico, after the dismantling of the import-substitution development strategy in the 1980's, caused a change in population patterns across the country, which led to industrial and population deconcentration trends away from Mexico City and towards the least urbanized areas in
} 
its sharp population increase must be attributed to its growing tourism industry, which grew to be the largest source of income and economic growth in the region, comprising nearly $80 \%$ of the state's GDP in 2008 (Carte et al., 2010).

Finally, it should be mentioned that the distribution of the population between the rural and urban sectors has experienced important changes. Therefore, it is possible to verify that, while Mexico's overall population has been rising, the rural population is on the fall (see Table 1), which is related in great part to the economic stagnation of the rural sector since the 1980 s, forcing people to move out from the countryside to the cities or abroad. According to the literature (Carte et al. (2010), Currit and Easterling (2009)), the magnitude of rural-urban migration in Mexico is considerable and increased after the country's insertion into the global economy, due to the development of emergent patterns of growth that favor economic activity in the urban sector while strongly discouraging that in the rural areas. ${ }^{15}$

\section{Within-Group Poverty AND ContRIBUtion to POVERTY ${ }^{16}$}

\section{EDUCATION}

Education, or human capital in general, is one of the factors determining the poverty level in a country, which is closely related to the condition of the poor. ${ }^{17}$

\footnotetext{
each region, paricularly northern Mexico. Accordingly, Mexico's nothern border cities have undergone enormous population growth mainly due to internal migration (Esparza et al., 2001), driven by growth in the maquiladora industry (Currit \& Easterling, 2009).

15 Visceral manifestations of economic status, improved welfare and material gains achieved through migration and remittances, stand out in the otherwise impoverished rural landscapes, serving as powerful signifiers of the asymmetrical opportunity structures afforded by migration as opposed to agricultural livelihoods in Mexico (Carte et al., 2010). Moreover, according to Currit \& Easterling (2009), as the population decline of the rural sector is followed by decreases in total available income, limiting economic opportunities and fostering declines in rural infrastructure, livelihoods and wellbeing, this results in additional pressure to migrate to places where job availability is perceived to be greater, as is the case of the Mexico's-northern-border industrialized cities (Currit \& Easterling, 2009) or the urban tourist poles of the Yucatan Peninsula (Carte et al., 2010).

${ }^{16}$ The percentage contribution to poverty is obtained by multiplying the headcount ratio for each category by its population weight - the percentage of the total population found in each category - and then dividing this by the overall headcount ratio (McKinley \& Alarcon, 1995). The reader is referred to Foster et al. (1984) for an implicit explanation of the methodology regarding all Foster-Greer-Thorbecke measures.

17 That higher educational attainment during youth leads to higher incomes later in life is probably the most documented finding in empirical microeconomics. At the same time, poverty leads to lower human capital formation through various mechanisms such as credit constraints, returns to education that increase markedly with the level of education,
} 
Consequently, there is a strong relationship between the educational-attainment level and poverty, which is usually accentuated in developing countries, ${ }^{18}$ where the lower the education level, the higher the probability of being poor. Mexico is a common example of this situation. This can be verified in Table 2 ("Overall Poverty" column), where up to 71,59 and $49 \%$ of households, whose head had no education or completed primary or junior-high school respectively, were poor in 1992 or 2008. Additionally, as shown in Figure 1 and Table 3, this was also true, regardless of the poverty line used, but the probability of being poor (contribution to poverty) with a basic educational level (primary and middle school) increased in the latter year, especially for lower-secondary school graduates, while it decreased by $20 \%$ points for people with no education. ${ }^{19}$ On the other hand, it is possible to corroborate as well that the probability of being poor while attaining an educational level equal to or higher than secondary education was small (less than 10\%) but increased considerably in 2008 (from 4.2 to $9.4 \%$ for overall poverty), and this situation is exacerbated the higher the value of the poverty line. ${ }^{20}$ Overall, we could not find great differences between the two analyzed years given the fact that it is mostly the unskilled population the one that was forced to stay poor due to its limited access to education during the whole period. ${ }^{21}$ Therefore, it is possible to corroborate that the strong correlation, identified in McKinley and Alarcon (1995), between lack or low levels of education and poverty is still present in Mexico.

underinvestment traps among others (Arias, 2006).

18 This occurs mostly in developing countries because rates of return increase sharply the higher the educational level and particularly so for college graduates (de Ferranti et al. (2003), IDB (2004), Bourguignon et al. (2005)). Consequently, this situation contributes to the increase in the skill-premium gap, between low- and high-skilled workers, which is definitely more pronounced in developing countries, where labor markets are far less developed, fiscal policy is much less progressive, and minimum wages are usually below subsistence levels. For instance, in Mexico, according to Mayer-Foulkes (2008), there are extraordinary (above equilibrium) returns to education and early child development, at levels not accessed by most of the population (about 75\%), contributing to the formation of an intergenerational human-development poverty trap.

${ }_{19}$ This occurred due to the educational-inequality decline observed in the country, attributed mainly to the sharp decreases in the proportion of adults with an educational level equal or less than some elementary school (Iniguez-Montiel, 2011).

20 As shown in Table 1, all of these changes are explained in great part by the education-distributional improvement that occurred during the period, decreasing the proportion of adults with no education dramatically while that of lower- and upper secondary cohorts rose correspondingly.

${ }^{21}$ According to Mayer-Foulkes (2008), there is a low human-capital development trap in Mexico; the poverty trap exists if a high enough proportion of the population suffers strong enough barriers to its access to human capital (education, health, nutrition among others). 


\section{OCCUPATION}

As shown in Table 4, the occupations with the highest proportion of overall poor households were, without doubt, agricultural workers with $81 \%$, followed by skilled- and unskilled-industrial workers and the unemployed with 55, 71 and $61 \%$, respectively, in 2008. Contrastingly, there was only one classification, standing out among all other occupations, whose population was mostly non-poor in either year by $95 \%$, and this has to do with the "Public Servants and Firm Managers" group.

Moreover, according to Figure 2, the situation in 2008 was not that different from that in 1992, as the poor families were mainly those whose head of household worked as agricultural workers, particularly those below the extreme (capacities) poverty line. For example, the figure shows that about 50 and $40 \%$ of the families considered as extremely poor were households whose head was employed as a laborer in the agricultural sector in 1992 and 2008 respectively. Additionally, it is also possible to corroborate in the figure and Table 3 that other households highly associated to the condition of being poor in both years were those whose head worked as industrial and self-employed workers, sellers or that were inactive. ${ }^{22}$ On the other hand, there are some occupations, in particular, that are not related to poverty in Mexico at all, implying that the heads of household employed in those jobs and their families have a high probability of being out of extreme and moderate poverty. Those occupations were the following in both years: arts, sports and entertainment workers; industrial supervisors and control workers; professional and technical workers, and professors; and public servants and firm managers.

It is possible to conclude, therefore, that the condition of being poor in Mexico is highly related to agricultural jobs or occupations that are associated to the unskilled or people with an educational level lower than secondary school, which

\footnotetext{
22 It should be noted, however, that the contribution to overall poverty of agricultural and industrial workers decreased over time due to the reduction in both the proportion of the poor among those workers (see Table 4) as well as the proportion of their respective populations (see Table 1). In contrast, as the population of the self-employed and service workers and sellers increased (see Table 1), their respective contributions to overall poverty rose consequently (see Table 3 ) even though the proportion of poor people among them decreased or stayed the same in 2008 as shown in Table 4.
} 
corroborates again the strong relationship between education and poverty in Mexico identified in the previous subsection.

\section{LOCATION}

There is an interesting pattern to be observed in Table 5, which shows the headcount index by state, considering extreme, moderate and overall poverty. First, it is evident that the proportion of extremely poor households was reduced considerably in at least 22 of the 32 Mexican states, increased significantly in Baja California Norte and only marginally in Quintana Roo and Sonora, while the rest of the states showed little or no variation. Consequently, extreme poverty at the national level decreased by 5\% points from 24 to $19 \%$ in 1992 and 2008 respectively. Second, in general, moderate poverty at the national level did not change in the long run because it increased in some states as often as it decreased in others, or, in some cases, remained practically unchanged. Therefore, we can conclude that the overall reduction in national poverty from 53 to $48 \%$ is mostly owned to the important decline of extreme poverty that was achieved in about $70 \%$ of the Mexican states. Moreover, as it is possible to corroborate in Table 6, the most important reduction in extreme poverty (around $10 \%$ points) during the analyzed period was mainly due to changes in the poverty level in the rural sector, while poverty decreased only by $2 \%$ points in the urban areas. On the other hand, however, moderate poverty increased by $4.6 \%$ points in the rural sector, ${ }^{23}$ and decreased by $1.7 \%$ points in the urban one, yielding a neutral-overall change at the national level.

As shown in Figure 3 (Graph 1), there are some Mexican states where traditionally the proportion of extremely poor households is concentrated. ${ }^{24}$ That

\footnotetext{
${ }^{23}$ The increase in moderate poverty within the rural sector should be attributed in part to the lack of government assistance besides that provided by the Oportunidades program, which aims at alleviating and reducing extreme poverty through conditional cash transfers and by investing in the human capital of poor households. Actually, the Mexican government has been criticized for reducing Mexico's social model to a system that is almost exclusively concerned with protection for those living in extreme poverty (Bayon, 2009). Therefore, it is most probable that, while some rural households are able to overcome their severely poor condition, they continue to be "moderately" poor as their income is insufficient to satisfy other basic necessities like clothing, decent shelter, transportation and recreation.

${ }^{24}$ The sample design of the ENIGHs does not provide statistical significance for each of the 32 Mexican states. Actually, the ENIGH's sample is only representative at the rural and urban levels, which are considered as those populations with less and more than 2,500 inhabitants respectively. Consequently, the results and interpretations made in this
} 
is the case, for example, of Chiapas, Estado de Mexico, Veracruz, Puebla, Oaxaca, Guerrero, Guanajuato and Michoacan whose contribution to national extreme poverty in 2008 was $11.5,11.2,10.1,7.5,6.0,5.5,4.8$ and $4.5 \%$ respectively. Coincidentally, the same states concentrated the highest proportion of the extremely poor in 1992 as well. This means that part of the central and southern regions, covering 8 states only, accommodate the majority $(61 \%$ in 2008) of the poorest households in the country. In contrast, the states with the lowest proportion of extremely poor families (Baja California Sur, Colima, Baja California Norte, Aguascalientes, Campeche, Quintana Roo, Queretaro, Morelos, Nayarit and Nuevo Leon) were mainly located in the northern regions in both years. This may be attributed in great part to the sectoral pattern of growth, which favors the northern states, over the southern ones, due to their proximity to the United States of America.

Additionally, it can be seen in Figure 3 (Graph 2) and Table 3 that the highest proportion of poor households, in terms of overall poverty, is mostly located in states like Estado de Mexico, Veracruz, Puebla, Chiapas, Jalisco, Mexico City, Guanajuato, Oaxaca, Michoacan and Guerrero, which individually contributed to national poverty by $13.8,8.2,6.8,6.3,5.4,5.2,5.0,4.4,4.0$ and $3.8 \%$ respectively, representing $63 \%$ of the total in 2008 . Again, it should be noted that those states are located in the central and southern regions of the country; however, the states that contributed the less to overall poverty are primarily those in the northern part of Mexico, which resembles the situation explained in the previous paragraph regarding extremely poor households.

Finally, it is possible to corroborate that the contribution to poverty of the rural sector declined from 37 to $34 \%$ in 1992-2008, and, consequently, that of the urban sector increased to $66 \%$ in 2008 (see Table 3). While the reduction in the contribution to overall poverty of the rural areas could be attributed to either the reduction of the population or the poverty decline in that sector, it is certain that the increase in the contribution to poverty of the urban sector is due to its population rise, given the fact that overall urban poverty declined in the analyzed period (see Table 6).

\section{The Evolution of Poverty, Inequality and Economic Growth in MeXico}

subsection should be considered with care and are just intended for informative purposes. 


\section{POVERTY}

As shown in Figure 4, the headcount ratio, as measured by any of the poverty lines considered, increased sharply after 1994, reaching its highest level in 1996. Thereafter, there was a remarkable change that caused the poverty level to decline continuously until attaining its lowest level of the analyzed period in 2006. However, the favorable (decreasing) trend observed since the mid-1990s was finally reversed in 2007-2008, locating the poverty levels around those found in 2000-2002.

Moreover, it is possible to corroborate in Figure 5 that, while overall poverty seems poorly correlated with moderate poverty, which remained approximately constant over the whole period (see Table 7), changes in total poverty were mostly determined by changes in extreme poverty in the short and long terms, ${ }^{25}$ confirming our results in the previous subsection.

\section{INEQUALITY}

The inequality considered in this study is that of total household per-capita income as represented by the Gini coefficient. Figure 6 shows the inequality trend followed in Mexico since 1984 in order to appreciate the sharp increase in inequality that took place in the mid-1980s. According to that figure, income inequality increased quite sharply between 1984 and $1989,{ }^{26}$ the Gini coefficient increasing from 0.49 to 0.54 , remained high during the 1990 s (fluctuating around 0.53 to 0.55 ), and, declining between 2000 and 2002, the Gini coefficient

\footnotetext{
${ }^{25}$ A similar conclusion can be drawn when analyzing absolute poverty in Mexico (see Table 7). However, in that case, it is possible to identify clearly that moderate poverty continuously increased from 5.5 to 7.8 million households in 1992-2008, which definitely had a negative impact on overall poverty. Nevertheless, it was the changes in extreme poverty once again the ones that were mostly responsible for the changes in overall poverty during the analyzed period, where a similar pattern as that portrayed in Figure 5, regarding extreme and overall poverty, is observed in the case of absolute poverty too. It should be noted that the same arguments apply to relative and absolute poverty in terms of persons. However, the figures increase dramatically if one considers persons in poverty instead of households (see Table 7).

${ }^{26}$ It is argued that income inequality, as well as poverty, rose in the years following 1984, after declining continuously since the mid-1960s, due to Mexico's economic-model change and the drastic economic policies implemented as a consequence of the 1982 financial crisis. For excellent reading on this, see Lustig (1992), Szekely (1998, 2005), Hernandez-Laos \& Velazquez-Roa (2003) and Rueda-Peiro (2009).
} 
dropping by 0.03 to 0.52 , remained approximately constant thereafter (Iniguez-Montiel, 2011).

In addition, it is clear in the figure that there were two main falls in the inequality measure; the first occurred in 1996 as a consequence of the 1994-1995 financial crisis (Cortes, 2003). The second and, actually, most important decline of income inequality during the whole analyzed period took place right after 2000 but, this time, it occurred through a combination of market forces and state action (Iniguez-Montiel, 2011). ${ }^{27}$ It will be shown later in the analysis that these two income-distributional changes, particularly the post-2000 one, had important poverty-reducing effects in Mexico.

\section{ECONOMIC GROWTH ${ }^{28}$}

According to Figure 7, economic fluctuations are quite common in Mexico's recent history. ${ }^{29}$ It is, therefore, possible to see in the figure that, after recovering from a recession in 1993-1994, the Mexican economy entered into a severe recession in 1995, which was mainly caused by the 1994-95 financial crisis. However, the economy recovered quite quickly in 1996, maintaining relatively high growth rates during the rest of the decade. After 2000 , there was another recession that lasted until 2003, and then, from 2004 to 2006, positive growth rates followed. Finally, in 2007-2008, an economic slowdown can be observed in the graph, which, according to INEGI's official figures, ${ }^{30}$ continued and worsened during the year 2009 (with negative GDP growth rates averaging

\footnotetext{
${ }^{27}$ According to Iniguez-Montiel (2011), income inequality in Mexico remained high in the 1990s mainly due to the unequalizing effect of the rates of return to assets (real and financial), demographics and education. On the other hand, the post-2000 income-distributional improvement was greatly associated with three factors: education (returns and distribution), financial assets (returns and distribution), and the betterment in the rates of returns to the rural areas and, in particular, the South of the country (Iniguez-Montiel, 2011).

28 Given that the micro data (ENIGH) used in this paper comes from a biannually conducted survey, we decided to show, in this subsection only, the information of the Penn World Table 6.3 (Heston et al., 2009) (corresponding to the period 1992-2007) and the 2008-INEGl's macroeconomic indicator, regarding the growth rates of real GDP per capita (grgdpch) and of GDP respectively, in order to have a clearer view of the performance of the Mexican economy during the analyzed period.

29 It should be noted that, according to the Penn World Table 6.3 (Heston et al., 2009), economic instability (volatility with negative growth rates) has been part of the Mexican economy since the early 1980 s.

${ }^{30}$ Economic Information Database, based on the Mexican National Accounts and available through INEGI's webpage at http://dgcnesyp.inegi.org.mx/bdiesi/bdie.html.
} 
$6.6 \%)$ and ended in the present year (2010) with positive growth rates.

Through the analysis carried out in this paper, we carefully explain how changes in economic growth and income inequality determined the changes in the poverty level in Mexico. For that purpose, we make use of standard decomposition techniques and other methodologies, which are explained in the following section and the appendix respectively.

\section{Methodology}

There are four methodologies that were applied in this study, which are explained below. But first, it is important to mention that, for the analysis of poverty made with two methodologies, ${ }^{31}$ we focus on poverty measures $(P)$ that can be fully characterized in a general form as follows:

$P_{t}=P\left(\mu_{t}, z, L_{t}\right)$,

where $\mu_{t}$ is the mean income, $\mathrm{z}$ is the poverty line and $L_{t}$ is a vector of parameters fully describing the Lorenz curve at date $t$.

\section{DECOMPOSITION OF POVERTY CHANGES INTO}

\section{GROWTH AND DISTRIBUTION COMPONENTS}

The first decomposition to be applied is the one of Datt and Ravallion (1992). This technique is of particular interest as it allows to identify the specific contribution of growth and income-distribution changes to poverty reduction between two periods for the Foster-Greer-Thorbecke (FGT) class of measures, namely the headcount index $(H)$, the poverty gap index (PG) and the FGT index, which are all additively decomposable (Foster et al., 1984). According to the methodology, a change in poverty over dates $t$ and $t+n$ can be decomposed into the growth and distributional effects as follows:

$$
\begin{aligned}
P_{t+n}-P_{t}= & G(t, t+n ; r)+D(t, t+n ; r)+R(t, t+n ; r) \\
& \text { (Growth Effect) (Distributional Effect) (Residual) }
\end{aligned}
$$

in which the growth and distributional effects are given by

31 These correspond to the decomposition of poverty changes into its growth and distribution components (Datt \& Ravallion, 1992) and the analysis of poverty in the medium and long terms (Chavez \& Gomez, 2009). 
$G(t, t+n ; r) \equiv P\left(z / \mu_{t+n}, L_{r}\right)-P\left(z / \mu_{t}, L_{r}\right)$,

$D(t, t+n ; r) \equiv P\left(z / \mu_{r}, L_{t+n}\right)-P\left(z / \mu_{r}, L_{t}\right)$,

while $R$ ( ) denotes the residual. ${ }^{32}$ In each case, the first two arguments in the parenthesis $(t$ and $t+n)$ refer to the initial and terminal dates of the decomposition period, and the last argument $(r)$ makes explicit the reference date with respect to which the observed change in poverty is decomposed.

Therefore, the growth effect of a change in the poverty measure is defined as the change in poverty due to a change in the mean while holding the Lorenz curve constant at some reference level $L_{r}$. The distribution effect is the change in poverty due to a change in the Lorenz curve while keeping the mean income constant at the reference level $\mu_{r}$ (Datt and Ravallion, 1992).

\section{Sectoral Decomposition of the Change in Poverty}

Tables 1 and 6 show that within-rural poverty decreased from 1992 to 2008 as well as the share of the rural population declined in this period. As it is not clear whether the decrease in poverty in Mexico is explained mainly by rural-urban migration or not, we apply a second decomposition, originally proposed by Ravallion and Huppi (1991), to decompose the changes in national poverty into a population-shift effect and a within-sector effect. The methodology aims to assess the relative gains to the poor within specific sectors and the contribution of changes in the distribution of the population across those sectors (Ravallion and Huppi, 1991). Letting $P_{t}$ denote the poverty measure for date $t$, while $P_{t}^{i}$ is the measure for sector $i=r, u$ (rural, urban), with corresponding population shares $n_{t}^{i}$, we can write an exact decomposition of the change in poverty as:

$$
P_{t+n}-P_{t}=\left[n_{t+n}^{r}\left(P_{t+n}^{r}-P_{t}^{r}\right)+n_{t+n}^{u}\left(P_{t+n}^{u}-P_{t}^{u}\right)\right]+\left[\left(P_{t}^{u}-P_{t}^{r}\right)\left(n_{t+n}^{u}-n_{t}^{u}\right)\right]
$$

(Within-sector Effect) (Population-shift Effect)

The within-sector effect is the change in poverty in each sector weighted by the final year population shares, while the population-shift effect measures the contribution of urbanization, weighted by the initial urban-rural difference in poverty measures. The population-shift effect should be interpreted as the partial

${ }^{32}$ Refer to Datt \& Ravallion (1992) for details on how to obtain the residual. 
effect of rural-urban migration, in that it does not allow for any effects of migration and remittances on poverty levels within rural and urban areas (Ravallion and Chen, 2007).

This methodology will be applied to the long-run period (1992-2008) and two consecutive periods in between the former, namely, 1992-2000 and 2000-2008, in order to be able to identify the within-sector and population-shift effects that occurred in Mexico. ${ }^{33}$

\section{Results}

\section{DECOMPOSITION OF POVERTY CHANGES INTO}

\section{GROWTH AND DISTRIBUTION COMPONENTS}

The proposed methodology in Datt and Ravallion (1992) was applied to the long-run period (1992-2008) and four consecutive and different periods in between the former. ${ }^{34}$ This could give us the possibility of identifying the specific contribution of the changes in the income inequality and economic growth to changes in the level of poverty in Mexico in the short, medium and long terms.

\section{Long-run period: 1992-2008}

Table 8 shows the results of the decomposition exercise for the five periods under analysis. As it is possible to corroborate in the table, there was a relatively even contribution of inequality and economic growth to the reduction of poverty between 1992 and 2008, especially within the food and capacities (extreme) poverty lines. On the other hand, for higher poverty lines, there seems to be a relative dominance of the economic-growth effect, contributing by $59 \%$ to the reduction of poverty. However, it should also be observed, that the contribution of the redistributive effect was not minor, accounting to by no less than $43 \%$ of

\footnotetext{
${ }^{33}$ As we have seen in previous sections, the relationship between growth, inequality and poverty seems to change in the 1990s and the 2000s. To highlight this change, we use two sub-periods: 1992-2000 and 2000-2008.

34 The four analyzed periods in between 1992-2008 correspond to 1992-1996, 1996-2000, 2000-2004, and 2004-2008. Our reason to divide the long-run period in this manner is that, as shown in Section 2, there were clearly two periods where income inequality declined (1992-96 \& 2000-04) and some other periods where economic growth was evidently achieved (e.g. 1996-2000 \& 2004-08). We believe this will facilitate our analysis and clarify in a better way the relationship between poverty, inequality, and economic growth in Mexico.
} 
the poverty decline in Mexico in the long-run period (see Figure 8). ${ }^{35}$

It is, therefore, possible to say that both changes in economic growth and in the distribution of income in Mexico were both important determinants of the reduction in the poverty level in 1992-2008 as suggested in the literature. This is particularly an important finding that confirms the positive and sizable impact of redistribution on poverty in Mexico, even though the reduction of income inequality after 2000 was less than 3 percentage points. Let us continue analyzing the decomposition results for the periods in between 1992-2008 to obtain more detail information in this respect.

\section{Decomposition: 1992-1996}

The results in Table 8, regarding the period 1992-96, give a rather different picture of the contribution of growth and inequality to poverty in Mexico. As shown in the table, changes in economic growth were completely responsible for the increase in the poverty level during the period, whereas, changes in the distribution of income acted as a cushion that prevented the level of poverty to rise even further.

We may recall that, during this period, there was a strong economic contraction that was the result of the 1994-95 financial crisis, the worst crisis since the 1930s according to the Bank of Mexico (1996). Additionally, the data shows that, as a result of the same crisis, income inequality in Mexico declined from a Gini coefficient of 54.3 to $52.7 \%$ in 1994 and 1996 respectively. ${ }^{36}$

Consequently, it is possible to say that changes in the distribution of income in the country had a positive and considerable impact on the level of poverty that partially counteracted the negative and strong effect of the economic recession. On the other hand, the negative growth rates that followed the 1994-95 crisis

\footnotetext{
35 To facilitate the analysis and for ease of understanding, only the results regarding the FGT index are shown in this and the following subsection. However, it must be noted that the complete analysis was carried out for the $\mathrm{H}$ and $P G$ indexes as well, obtaining similar results to those for the FGT measure. As our main concern is about the impact of inequality on poverty, the FGT index constitutes the most appropriate measure to be considered without doubt, given the fact that, as opposed to the other two indexes, inequality among the poor is fully accounted within this indicator (Foster et al., 1984). The complete decomposition results are available from the author upon request.

${ }^{36}$ See Table 7 and Figure 6.
} 
mainly contributed to the formation of the highest poverty levels ever recorded in Mexico since 1950 (Szekely, 2005).

\section{Decomposition: 1996-2000}

It is possible to see in the same table, that the opposite effects from those found for the period 1992-96 occurred in this latter period. ${ }^{37}$ Therefore, while economic growth contributed positively to the reduction of poverty in Mexico, changes in the distribution of income (inequality rise) had a poverty-increasing effect, which is consistent with economic theory and reasoning again, at each of the poverty lines considered. Thus the decline of the poverty level during 1996-2000 was due to the strong and positive contribution of the growth effect, which was substantially diminished by the higher concentration of income that happen to prevail in the period. Consequently, it may be possible to say that an income-distribution deterioration in Mexico drastically reduces the positive impact of growth on poverty.

\section{Decomposition: 2000-2004}

The results for the period 2000-04, shown in Table 8, are similar to those obtained for the long-run period (1992-2008). However, it is possible to see in the table that the growth effect dominates the redistribution effect at every poverty line considered. Nevertheless, the poverty-reducing effect of the inequality decline was fairly large as well. Consequently, both changes in the growth and the distribution of income contributed to the considerable decline of poverty in Mexico during 2000-04.

It should be noted that the abovementioned effects on poverty were achieved through a combination of positive economic growth and the improvement in the distribution of income in Mexico after 2000, which is a different cause of the poverty reduction observed before 2000 .

\section{Decomposition: 2004-2008}

As shown in Section 2, this latter period marks the end of a continuous decline in

\footnotetext{
${ }^{37}$ It should be noted, however, that, as explained in Cortes et al. (2002), the growth effect continued to be the dominant factor in this latter period, determining the change in the poverty level in 1992-2000.
} 
the level of poverty since 1996. According to the data, the poverty reduction ended in 2006 and was followed by a sharp increase in the level of absolute and relative poverty in 2008 (see Table 7), similar to, or even higher than, the levels recorded in 2000 and/or in the early 1990's. This dramatic reversal of the poverty level, which is said to have worsened in 2009 and 2010, provides evidence of the vulnerability of the Mexican economy to external shocks (or financial crises) and of the inherent weaknesses in the country's development strategy.

According to Table 8, the worsening in the level of extreme poverty in 2004-08 was primarily caused by the income-growth effect, implying that the mean-income (per-capita) level was lower in 2008 than in 2004 due to decreasing growth rates in the latter year. Moreover, the distribution effect also contributed, although minimally, to the rise in the poverty level. This means that income inequality among the poorest households in Mexico increased, affecting adversely the extremely poor. ${ }^{38}$ Contrastingly, if we analyze the basic-needs and overall poverty, then the distributive effect had a positive impact on poor households, which somehow counteracted the stronger, negative effect of the changes in economic growth during the period. ${ }^{39}$

\section{Sectoral Decomposition of the Change in Poverty $^{40}$}

\section{Long-run period: 1992-2008}

According to the decomposition results in Table 9, the reduction in the level of extreme poverty in the long-run in Mexico was mainly determined by the poverty

\footnotetext{
${ }^{38}$ The inequality rise for households below the $25^{\text {th }}$ percentile of the income distribution as well as the per-capita income decline at each percentile of the distribution in 2004-08 were both corroborated with the data.

39 It is important to mention that our results for this latter period are supported in Hernandez-Licona (2010). However, Hernandez-Licona (2010) finds that the increment in the level of poverty in 2008 was additionally determined by the relative increases in food prices in Mexico as well. This can be easily identified by comparing the value of the 2004 and 2008 poverty lines at constant prices. But, as the decomposition methodology proposed by Datt and Ravallion (1992) assumes a constant, exogenously-determined, poverty line within the model, the changes in the value of the poverty line over time are not considered in this study.

40 The decomposition exercises in this subsection were performed with respect to people and not to households in poverty, as was done in the previous subsection, so that the population-shift effect is more meaningful. Consequently, the total changes in poverty shown in both types of decompositions, particularly the ones corresponding to the long-run period, are not identical.
} 
changes (poverty decline) within the rural sector and the changes in the distribution of the population between the rural and urban sectors. Between these two effects, it was definitely the rural-sector effect the one with the highest contribution (67\%). Nevertheless, the population-shift effect also contributed in an important manner to the reduction of extreme poverty, accounting to about $30 \%$ of the decline, while the changes in poverty within the urban sector were mainly unimportant (see Figure 9).

On the other hand, when higher poverty lines are evaluated, it is still the decline in rural poverty the main, dominating effect, with an overall contribution to national poverty of about $40 \%$. However, this time, the reduction of poverty within the urban sector turns out to be more important for the determination of poverty, with a sizable impact of $35 \%$, than the changes associated to the distribution of the population, which had an average, positive contribution of $27 \%$ in the period.

In order to have a clearer picture of the effects considered in this decomposition, the exercise was carried out for two different and consecutive periods in between 1992-2008. These periods correspond to 1992-2000 and 2000-2008, whose results are explained in the following lines.

\section{Decomposition: 1992-2000}

In this former period, it is evident that the increases in poverty in the rural sector were mostly responsible for the rise in national poverty, regardless of the poverty line that is used (see Table 9). Therefore, when analyzing food and capacities poverty, the combined negative effect of rising poverty in the rural and urban sectors, but especially in the former, caused the sharp increase in extreme poverty observed at the national level, while the changes in the distribution of the population between sectors partially, although minimally, counteracted the negative impact.

On the other hand, even though the changes in urban poverty, together with the population-shift effect, had a positive and considerable effect on poverty (beyond the extreme-poverty line), basic-needs and overall poverty did actually augment 
due to the strong, negative impact of increasing poverty in the rural areas. ${ }^{41}$

\section{Decomposition: 2000-2008}

A completely different picture emerges from the sectoral decomposition in 2000-08 (see Table 9), especially with respect to the changes in poverty within the rural sector. In this latter period, the estimated reduction in national poverty was mainly associated to the decline of poverty within the rural sector, in stark contrast with the decomposition results obtained for the former period.

As for the changes in poverty in the urban sector, they also contributed positively to decreasing national poverty although to a much lower degree than the changes in rural poverty that were observed. Moreover, the population-shift effect was positive, as usual, along the whole decomposition exercise, contributing in an important manner to the decline of national poverty and being the second most important determinant of the level of extreme poverty, after the rural-sector effect, in 2000-08.

In the following subsection, it will become clearer the reason of the sudden and positive change that was experienced within the rural sector in particular, which actually caused the level of poverty to decline until 2006, and even during the economic recession that occurred in 2001-2003.

\section{MEASURING PRO-POOR GROWTH ${ }^{42}$}

In order to have a better understanding of the changes in national, rural and urban poverty, we made use of the Growth Incidence Curves (GICs), which show the income-growth rates of households at each percentile of the distribution, and additionally measured the rate of pro-poor growth in Mexico during 1992-2008, 1992-2000, and 2000-2008.

\footnotetext{
${ }^{41}$ It is possible to affirm that the sharp rises in rural poverty, determining the poverty increase at the national level in 1992-2000, were the direct result of the severe economic contraction that followed the 1994-95 crisis and the high inequality levels that persisted during the 1990s. Therefore, both effects (growth and distribution) affected adversely the poor in Mexico, but mostly those in the rural sector, during the period. This situation is actually corroborated in the following subsection: "Measuring Pro-poor Growth".

${ }^{42}$ Growth is considered pro-poor if, in addition to reducing poverty, it also decreases inequality (Nissanke \& Thorbecke, 2006). Refer to the appendix for an explanation on how to measure pro-poor growth.
} 


\section{National Level}

By looking at the GICs for the different analyzed periods, it is possible to corroborate the sectoral-decomposition results explained in the previous subsection. The GIC for the long-run period (Figure 10) shows that it was the poor-income households (those below the $40^{\text {th }}$ percentile of the income distribution) the ones whose income grew at higher rates during the whole period at the national level. According to our calculations (see Table 10), the rate of pro-poor growth for poor-income households was $22.5 \%$, compared to the $13.3 \%$ growth rate in average income that was observed during the period. Moreover, it is also possible to see in the same figure that, while the income of the richer families grew at below-average rates, above-average income-growth rates were attained by middle-income households in general. We can, therefore, conclude that growth in 1992-2008 was absolutely pro-poor, meaning by this that the dynamic process adopted in Mexico was able to reduce poverty and inequality at the same time. Let us analyze the GIC curves for the periods in between the long run in detail in order to obtain more information on this issue.

Figure 11 portrays the national GICs for the periods 1992-2000 and 2000-08. As it is possible to confirm in that figure, the period 1992-2000 was characterized by pro-rich growth and negative growth rates for households below the $95^{\text {th }}$ percentile of the income distribution. Contrastingly, in 2000-08, growth was definitely pro-poor $(25.4 \%$ (see Table 10$)$ ), with positive growth rates for all households below the $95^{\text {th }}$ percentile and negative ones for those at the top $5^{\text {th }}$ percentile.

This means that, while there was an income distributional worsening in 1992-2000 where most of the gains from growth, if not all, were captured by the highest-income groups, an important decline in income inequality took place in 2000-2008, affecting positively middle- but, especially, lower-income families, which caused the decline in national poverty that was observed in the latter period. Therefore, growth with redistribution, or pro-poor growth, was the key to achieve the considerable decline in the poverty level after 2000 in Mexico.

\section{Rural \& Urban Sectors}

By analyzing the 1992-2000 and 2000-2008 GICs for the rural and urban 
sectors separately, it is possible to observe a similar pattern than the one obtained at the national level. This gives us additional information as to why the growth and inequality changes within both sectors contributed to the rise and decrease of national poverty in 1992-2000 and 2000-08 respectively.

As shown in Figure 12, income growth was mainly negative for rural households below the $93^{\text {rd }}$ percentile of the distribution in 1992-2000, and only positive from there on. While the average growth rate was actually negative by $0.1 \%$, the rate of pro-poor growth was much lower $(-7.5 \%)$ for households below the $40^{\text {th }}$ percentile (see Table 10). Consequently, during this period, growth was only attained by higher-income households, which explains to a great extent the inequality rise that was observed as well as the increase in the level of poverty in the rural sector.

On the other hand, there was a drastic change that occurred in the rural sector in 2000-08 (see Figure 12), which shifted the gains from growth to above-average levels for lower- and middle-income households, as opposed to the former period, causing an improvement in the distribution of income that was responsible for the decline of poverty within that sector.

Moreover, Figure 13 shows a pretty similar picture to the one explained for the rural sector. Therefore, growth in the urban sector was not pro-poor in 1992-2000, while it was definitely so during the latter period but at lower growth rates (the average- and pro-poor growth rates were 8.8 and $13.4 \%$ respectively) than in the rural sector, where the average- and pro-poor growth rates were 26.6 and $39.1 \%$ respectively in $2000-08$ (see Table 10 ). Thus, economic growth and the income-distributional improvement that occurred after 2000 both determined the income-poverty decline in the urban sector in 2000-08 as well.

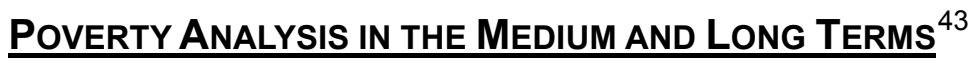

This final analysis, which is based on the application of the methodology proposed by Chavez and Gomez (2009), has as one of its main purposes to prove that, by maintaining a high level of inequality in Mexico, the reduction of poverty through growth (especially low growth as the one achieved in the

43 The methodology for the analysis of poverty in the medium and long terms is included in the appendix. 
country in the last three decades (Heston et al. (2009), Levy and Walton (2009), Arias et al. (2010)) is indeed limited as suggested in the literature (Ravallion (1997, 2005), Hanmer and Naschold (2000), Oxfam (2000), Addison and Cornia (2001), Bourguignon (2004), Lopez (2006) among others). ${ }^{44}$

Even though, the point was implicitly and partially proven by Chavez and Gomez (2009) for food poverty, using the 2005 ENIGH data, we consider it is appropriate to show the results by using the most recent available information and considering higher poverty lines, which could be said to be more relevant to the study of poverty in Mexico given its current level of development. Therefore, our analysis consists in determining the required time and necessary growth rate to eradicate extreme and overall poverty given the conditions in Mexico in 2008. We carried out the analysis for the H, PG and FGT indexes at the national, rural and urban levels. However, only the results regarding the $\mathrm{H}$ index are shown in here as they resemble those for the other poverty measures considered.

\section{Eradicating Extreme Poverty}

Table 11 shows our results regarding extreme poverty in Mexico. It can be seen in that table that if the country maintained an average income per-capita growth rate of $1 \%$, given a capacities poverty line of $\$ 1,149$ pesos (at July 2009 constant prices) and an inequality level of $52 \%$ measured by the Gini coefficient, poverty in Mexico could be eradicated in about 70 years. Analogously, if that poverty goal were targeted in a more reasonable time horizon of 20 years, extreme poverty in Mexico could be overcome by achieving an annual growth rate in the mean income of $3.6 \%$.

The first of the above-mentioned scenarios does not seem so implausible at the national level given the fact that the annual, average income growth rate in Mexico in 1992-2008 was around $0.83 \%$ and increased to $1.51 \%$ in $2000-08$ (see Table 10: "Growth rate in the mean income"). However, if extreme poverty were to be eradicated in the medium term or within one generation (20 to 30

\footnotetext{
${ }^{44}$ Poverty reduction through growth is limited when income and assets inequality are high; growth is then concentrated in a few groups, bypasses poor smallholders and microentrepreneurs, and creates little employment for the unskilled. It is not surprising, for example, that Latin America's poor have derived so little benefit from its periods of growth. Growth must be very fast indeed to achieve any poverty reduction when a society exhibits both high initial inequality and rising inequality (Addison \& Cornia, 2001).
} 
years), then the average per-capita income in the country would have to grow at a faster pace indeed or, at least, the double of what it has grown in the last decade.

Similarly, if the Mexican government aimed at eradicating poverty in the rural areas within 20 years (see Table 11), an annual growth rate in the mean income of $5.9 \%$ would be needed, which is about 4 times the rate of growth achieved in that sector since the early 1990s (see Table 10). Additionally, if the average per-capita income in the rural sector grew at only $1 \%$ per year, extreme poverty could be eliminated in approximately 115 years. However, if current trends in income per-capita growth rates persisted, resembling those observed during 2000-08 for the rural areas, ${ }^{45}$ poverty eradication would be attained in less than 40 years, which is still far less encouraging than it sounds given the low value of the (monthly) extreme poverty line of $\$ 876$ pesos, or $\$ 66.1$ dollars ( $\$ 2.2$ dollars a day), at July 2009 constant prices. ${ }^{46}$

Likewise, the eradication of extreme poverty in the urban sector seems an unlikely event in the medium term as well. Most likely, as shown in Table 11 and given the growth rate in the mean income achieved within the last decade in that sector (see Table 10), it would take about 42 years for Mexico to overcome its severely poor condition if the high income disparities observed in the past remained unchanged due to distributionally neutral growth. On the other hand, a relatively low annual growth rate in average incomes of $2.1 \%$, or twice the rate of growth in 2000-08, would be necessary to eliminate extreme poverty in the urban sector in just 20 years.

\section{Eradicating Overall Poverty}

Table 12 shows a quite similar picture to the one presented above. However, the results increased considerably as we are dealing now with the more difficult problem of eliminating overall poverty. Therefore, in order to eradicate poverty in

\footnotetext{
${ }^{45}$ According to our calculations, the annual growth rate in the mean income per capita in the rural sector was around $3.3 \%$ in $2000-2008$, or $26.6 \%$ during the whole period (see Table 10).

${ }^{46}$ For the conversion of the poverty line into dollars, an exchange rate of $\$ 13.26$ pesos was applied, representing the rate determined by the monetary authority on July 31,2009 . It was obtained from the Bank of Mexico's web page at the following address: http://www.banxico.org.mx/portal-mercado-cambiario/index.html.
} 
Mexico in 50 years, given a constant poverty line of $\$ 2,318$ pesos and an inequality level of $52 \%$ (Gini), average incomes must grow at an annual rate of about $2.8 \%$. Nevertheless, if they grew at only $1 \%$ on average, overall poverty would be overcome in as many as 141 years.

Of course, the results obtained for the rural sector were more dramatic than those for the nation as a whole, and the ones related to the urban sector were relatively less so. Consequently, in order to eradicate total poverty in the rural and urban sectors, it would take approximately 180 and 113 years respectively if per capita incomes grew at $1 \%$ per year in each sector. On the other hand, if the poverty goal of eradicating overall poverty in the rural and urban areas were targeted on a more sensible time horizon of 50 years, average incomes would have to grow at 3.6 and $2.3 \%$ per year respectively, which again points towards the great challenge that the Mexican government faces at generating the necessary level of economic activity within both sectors as well as a more equitable pattern of growth between them. Perhaps, this could be partially accomplished by promoting the urgent development of the agricultural sector (where most of the have-nots happen to be), ${ }^{47}$ along with the creation of well-remunerated, quality jobs that could match the increasing supply of new entrants into the labor market, equivalent to over 1.3 million people each year (Hernandez-Laos \& Velazquez-Roa, 2003). By doing so, Mexico will be able to cope with the severe problem of its huge and increasing informal sector, ${ }^{48}$ and to induce a more equitable distribution of income and assets, which seems to be at the core of a successful development strategy for the country (Levy and

\footnotetext{
47 According to McKinley \& Alarcon (1995), who made a poverty profile of Mexico for the year 1989, rural wage workers and peasants of Mexico were the most numerous among the poor and experienced the greatest depths and severity of poverty. It seems that this situation has not changed much since then as corroborated in the present study (see Mexico's poverty profile in Section 2). Moreover, the authors explained that poverty cannot be expected to decrease as long as agriculture is a stagnant, low-productivity, crisis-ridden sector, and that the revitalization of agriculture is key not only to poverty reduction, but also to the development of Mexico as a whole (McKinley \& Alarcon, 1995). The previous statement is complemented by Carte et al. (2010), who suggest building on a more sustainable and truly regional economic development model in Mexico that supports rather than abandons regional agriculture, which has been systematically discouraged while the development in the urban core is systematically advantaged.

${ }^{48}$ Informal employment in Mexico represented $40 \%$ of the labor force by 2003 and is constituted by individuals in the non-agricultural sector that form two large types of groups: the "precarious employment" and the "workers without any fringe benefit" (Samaniego, 2005). According to ILO (2007), the figure increased to $45.4 \%$ in 2006.
} 
Walton (2009), Iniguez-Montiel (2011)). ${ }^{49}$

\section{Conclusions}

This study attempts to estimate the contribution of changes in economic growth and in the distribution of income to poverty reduction in Mexico during 1992-2008 by using standard decomposition techniques and other methodologies that have been proposed to analyze the, sometimes, overlooked and underestimated impact of inequality on poverty. Our findings point clearly to the important role of redistribution and the level of inequality for reducing poverty in Mexico, either in the short, medium or long term, as suggested in the literature. Thus, in addition to the poverty-reducing effect of growth that was identified, our results show that the observed decline of income inequality contributed quite evenly to the reduction of extreme poverty and had an important, sizable impact on decreasing overall poverty in the long run as well.

Over the short to medium term, the relative improvement in the distribution of income, representing a decline of less than 3 percentage points in the Gini coefficient after 2000 , was able to explain a large part of the reduction in poverty in 2000-2004 and partially counteracted the strong, poverty-augmenting effect of decreasing per-capita income in 2004-2008.

Moreover, we could also identify that the poverty reduction in Mexico after 2000 was greatly attributed to the poverty decline in the rural sector, which is associated to a $39 \%$ pro-poor growth rate for households below the $40^{\text {th }}$ percentile of the income distribution in 2000-2008. On the other hand, growth was also pro-poor in the urban sector during the same period but it was only a third $(13 \%)$ of that observed in the rural areas. Nevertheless, it also contributed to reducing poverty at the national level.

Therefore, we could conclude that growth with redistribution was indeed the key to reducing poverty continuously and in an important manner during 2000-2006,

\footnotetext{
${ }^{49}$ Mexico will be unable to cope with the risk of social fracture it faces today unless its economic and social development strategy is redirected towards a solidarity-based inclusive model that cannot only provide for the most disadvantaged groups, but also reduce poverty, vulnerability and the shocking differences in opportunity that so typify the Mexican society (Bayon, 2009).
} 
which corroborates what has been suggested in the literature about the important contribution of an improved distribution of income (lower inequality) to poverty reduction, particularly in highly-unequal developing countries (Ravallion (1997, 2005, 2007), Oxfam (2000), Addison and Cornia (2001), Bourguignon (2004), Lopez (2006)). Additionally, our results indicate as well that the high levels of inequality that persisted during the 1990s diminished considerably the poverty-reducing impact of growth that was achieved throughout the decade but, especially so, in 1996-2000.

Furthermore, an additional factor, which invariably had a considerable and positive impact on poverty in Mexico during the whole analyzed period (1992-2008), was the "Kuznets process" of migration (Ravallion and Chen, 2007) or the changes in the distribution of the population between the rural and urban sectors. Overall, this important factor contributed to about $25 \%$ of the reduction in national poverty, meaning that the decline of poverty in Mexico is partly caused by the population transfer from the traditional to the modern sector of the economy. Unfortunately, for the case of Mexico and due to the sluggish performance of the Mexican economy since the 1980s (Levy and Walton (2009), Arias et al. (2010)), this does not necessarily mean that there is less poverty in the country but a slow down of the rate at which poverty is reduced in the urban sector, which increases in size constantly and where a huge and increasing portion of the labor force (45\% in 2006 (Bayon, 2009)) is employed in the informal economy.

Finally, an important conclusion that can be reached is the one related to the necessity of continuing with the effort of decreasing the high levels of income inequality that persist in the country (Iniguez-Montiel, 2011), not only on equity (moral) but on economic efficiency grounds as well (Aghion et al. (1999), Oxfam (2000), Cornia et al. (2004), Cullity (2004), Dagdeviren et al. (2004), Culpeper (2005), van der Hoeven (2008), Levy and Walton (2009)), in order to eliminate gradually, but effectively, the poverty suffered by Mexico's $57 \%$ of the population (61 million people in 2008) and, in this way, accelerate the development process in the country. It is partly true that the majority of the population in Mexico remains poor due to the failure of the economy to grow at potentially higher rates, which could relocate the country out of its divergent, development path (OECD, 2009). However, on the other hand, the rather high levels of poverty that 
continue to prevail in the country are definitely the reflection of the great concentration of income and assets (wealth) that lies in quite a few hands, constraining the vast majority of people from benefiting from the gains of growth and realizing its full potential, in most of the cases because of the low human-capital accumulation trap that is present in the economy (Mayer-Foulkes, 2008).

Consequently, recognizing the importance of growth with equity is crucial for overcoming absolute poverty in Mexico in the foreseeable future, as it is most probably the case of middle-income, high-inequality countries too. According to our results, and based on economic theory, if the actual level of inequality (Gini of $52 \%$ in 2008) were to be maintained, poverty in Mexico could only be reduced via economic growth, at particularly high growth rates for the rural sector. Therefore, it seems that the most appropriate strategy for achieving a significant and permanent reduction in the poverty level has to do with the one that, in addition to promoting the economic development of the rural sector long-ago indicated in McKinley and Alarcon (1995), focuses on improving the distribution of income further, so as to reduce the high income disparities that persist in the country across individuals and regions (World Bank (2007), Levy and Walton (2009), Iniguez-Montiel (2011)) and between the rural and urban sectors as well. No doubt, this could only be achieved by pursuing an active pro-poor growth policy that takes into consideration the combined effects of growth and inequality on poverty, as well as the sectoral composition of growth in Mexico.

\section{APPENDIX}

\section{MEASURING PRO-POOR GROWTH}

By using the Growth Incidence Curves (GICs) suggested by Ravallion and Chen (2003), we intend to analyze and measure the rate of pro-poor growth that was achieved in Mexico during 1992-2008 and two different sub-periods in between the former: 1992-2000 and 2000-2008. This will give us the possibility of assessing how the gains from aggregate economic growth were distributed across households according to their initial incomes but, in particular, those accruing to the households considered as poor in Mexico according to different poverty lines. Additionally, the GICs will allow us to deepen our understanding of inequality in Mexico by graphically identifying the income distribution changes 
that took place along the whole distribution of income during the analyzed periods. This will facilitate our study of the relationship between poverty and inequality.

Following Ravallion and Chen (2003) we have that, if comparing two dates, $t-1$ and $t$, the growth rate in the income of the pth quantile is $g_{t}(p)=\left[y_{t}(p) / y_{t-1}(p)\right]-1$. Letting $p$ vary from zero to one, $g_{t}(p)$ traces out what is called the 'growth incidence curve' (GIC). Following Gastwirth (1971) we have that $y_{t}(p)=F_{t}^{-1}(p)=L_{t}^{\prime}(p) \mu_{t} \quad\left(y_{t}^{\prime}(p)>0\right)$, where $L_{t}(p)$ is the Lorenz curve and $\mu_{t}$ is the mean income of the distribution. Therefore,

$g_{t}(p)=\frac{L_{t}^{\prime}(p)}{L_{t-1}^{\prime}(p)}\left(\gamma_{t}+1\right)-1$

where $\gamma_{t}=\left(\mu_{t} / \mu_{t-1}\right)-1$ is the growth rate in $\mu_{t}$.

Then, the rate of pro-poor growth can be measured as the mean growth rate for the poor as follows: $\int_{0}^{H_{t}} g_{t}(p) d p / H_{t}$, which is the actual growth rate multiplied by the ratio of the actual change in the Watts index to the change that would have been observed with the same growth rate but no change in inequality (Ravallion and Chen, 2003).

\section{ANALYSIS OF POVERTY IN THE MEDIUM AND LONG TERMS}

Chavez and Gomez (2009) developed a methodology to analyze the feasibility of reaching different poverty goals, under different growth scenarios, by calculating the required time and the minimum necessary growth rate to meet the desired targets as follows:

Let $P^{*}$ be a poverty goal. The needed mean income, $\mu^{*}$, to meet this poverty goal for a given income distribution, L, and an exogenous poverty line, $\mathrm{z}$, is defined as: 
$\mu^{*}=\inf \left\{\mu: P(\mu, z, L) \leq P^{*}\right\}$.

Therefore, the time taken to meet the poverty goal, $P^{*}$, given $\mu, \mathrm{L}, \mathrm{z}$, and an annual per capita growth rate, $\bar{g}$, can be written as:

$$
t(\bar{g})=\ln \left(\left(\frac{\mu^{*}}{\mu}\right)^{1 / \ln (1+g)}\right) \text {. }
$$

Analogously, the minimum necessary growth rate of per capita income, $g(\bar{t})$, to meet the poverty goal, $P^{*}$, in $\bar{t}$ years, holding both the income distribution and the poverty line constant, is:

$$
g(\bar{t})=\left(\frac{\mu^{*}}{\mu}\right)^{1 / \bar{t}}-1 .
$$

It should be noted that Chavez and Gomez (2009) calculated the required time and grow rate to halve poverty incidence and intensity in Mexico, considering the one- and two-dollar a day poverty lines, as well as the official food poverty line. In this respect, our analysis departs from theirs in two important aspects. First, we consider two additional, higher poverty lines, which could be said to be more relevant to the study of poverty in Mexico, given its current level of development, and that are related to capacities (extreme) and overall poverty. ${ }^{50}$ Second, we are not only interested in estimating the required time and growth rate that are necessary to halve poverty in Mexico but our analysis mainly focuses on the eradication of poverty, considering the abovementioned poverty lines.

\section{References}

Addison, T. and G. A. Cornia (2001), "Income distribution policies for faster poverty reduction", UNU-WIDER Discussion Paper 2001/93. Helsinki: UNU-WIDER.

Aghion, P., E. Caroli and C. Garcia-Penalosa (1999), "Inequality and Economic Growth: The Perspective of the New Growth Theories", Journal of Economic Literature, 37 (4): 1615-1660.

\footnotetext{
${ }^{50}$ Refer to Section 2 for the definition of the poverty lines considered and information on how to obtain them.
} 
Alesina, A. and D. Rodrik (1994), "Distributive Politics and Economic Growth", Quarterly Journal of Economics, 108: 465-490.

Arias, J., O. Azuara, P. Bernal, J. J. Heckman and C. Villarreal (2010), "Policies to Promote Growth and Economic Efficiency in Mexico", NBER Working Paper Series, Working Paper 16554, November.

Arias, O. S. (2006), "Breaking the Cycle of Underinvestment in Human Capital in Latin America". In G. E. Perry, O. S. Arias, J. H. Lopez, W. F. Maloney and L. Serven (eds.), Poverty Reduction and Growth: Virtuous and Vicious Circles, The World Bank: Washington.

Banerjee, A. and A. Newman (1993), "Occupational Choice and the Process of Development”, Journal of Political Economy, 101 (2): 274-298.

Bank of Mexico (1996), Informe Anual 1995, Banco de Mexico: Mexico City.

Bayon, M. C. (2009), "Persistence of an Exclusionary Model: Inequality and Segmentation in Mexican Society", International Labour Review, 148 (3): 301-315.

Benabou, R. (1996), "Inequality and Growth", in B. Bernanke and J. Rotemberg (eds), National Bureau of Economic Research Macroeconomics Annual, Cambridge: MIT Press, 11-74.

Bourguignon, F. (2004), "The Poverty-Growth-Inequality Triangle", mimeo, The World Bank.

F. Ferreira and N. Lustig, (2005), The Microeconomics of Income Distribution Dynamics in East Asia and Latin America, The World Bank: Washington.

Carte, L., M. McWatters, E. Daley and R. Torres (2010), "Experiencing agricultural failure: Internal migration, tourism and local perceptions of regional change in the Yucatan peninsula", Geoforum, 41: 700-710. 
Chavez, J. and M. Gomez (2009), "Halving Poverty in Mexico", Economia Mexicana Nueva Epoca, 18 (1): 107-121.

Cornia, G. A., T. Addison and S. Kiiski (2004), "Income Distribution Changes and Their Impact in the Post-Second World War Period". In G. A. Cornia (ed.), Inequality, Growth, and Poverty in an Era of Liberalization and Globalization, UNU-WIDER and UNDP, Oxford University Press: Oxford.

Cortes, F. (2003), "El ingreso y la desigualdad en su distribucion. Mexico: 1977-2000", Papeles de Poblacion, 35 (January-March): 137-53.

D. Hernandez, E. Hernandez-Laos, M. Szekely and H. Vera (2002), "Evolucion y caracteristicas de la pobreza en Mexico en la ultima decada del siglo XX", Serie: Documentos de Investigacion, SEDESOL: Mexico City.

CTMP (2002), "Medicion de la Pobreza: Variantes Metodologicas y Estimacion Preliminar", Serie: Documentos de Investigacion, SEDESOL: Mexico City.

Cullity, G. (2004), "Equality and Globalization". In K. Horton and K. Patapan (eds.), Globalization and Inequality. Routledge: London.

Culpeper, R. (2005), "Approaches to Globalization and Inequality Within the International System", United Nations Research Institute for Social Development, Overarching Concerns Program, Paper No. 6.

Currit, N. and W. Easterling (2009), "Globalization and population drivers of rural-urban land-use change in Chihuahua, Mexico", Land Use Policy, 26: 535-544.

Dagdeviren, H., R. van der Hoeven and J. Weeks (2004), "Redistribution Does Matter". In A. Shorrocks and R. van der Hoeven (eds.), Growth, Inequality, and Poverty: Prospects for Pro-poor Economic Development, Oxford University Press: Oxford.

Datt, G. and M. Ravallion (1992), "Growth and Redistribution Components of Changes in Poverty Measures: A Decomposition with Applications to Brazil and 
India in the 1980s", Journal of Development Economics, 38: 275-295.

de Ferranti, D., G. Perry, I. Gill, J. Guasch, W. Maloney, C. Sanchez-Paramo and N. Schady (2003), Closing the Gap in Education and Technology, The World Bank: Washington.

Deininger, K. and L. Squire (1998), "New Ways of Looking at Old Issues: Inequality and Growth", Journal of Development Economics, 57 (2): 259-297.

Easterly, W. (2007), "Inequality does cause underdevelopment: Insights from a new instrument", Journal of Development Economics, 84: 755-776.

Esparza, A. X., J. Chavez and B. Waldorf (2001), "Industrialization and land use change in Mexican border cities: the case of Ciudad Juarez, Mexico", Journal of Borderland Studies, 16 (1): 15-30.

Foster, J., J. Greer and E. Thorbecke (1984), "A Class of Decomposable Poverty Measures", Econometrica, 52: 761-765.

Galor, O. and J. Zeira (1993), "Income Distribution and Macroeconomics", Review of Economic Studies, 60 (1): 35-52.

Gastwirth, J. L. (1971), "A general definition of the Lorenz curve", Econometrica, 39 (6): 1037-1039.

Hanmer, L., and F. Naschold (2000), "Attaining the International Development Targets: Will Growth Be Enough?”, Development Policy Review, 18 (1): 11-36.

Hernandez-Laos, E. and J. Velazquez-Roa (2003), Globalizacion, desigualdad y pobreza: Lecciones de la experiencia mexicana. Universidad Autonoma Metropolitana, Plaza y Valdez Editors: Mexico City.

Hernandez-Licona, G. (2010), "Pobreza y Desarrollo Social: avances y retos en Mexico". In Sepulveda-Villarreal (ed.), Temas Economicos y Sociales de Actualidad en Mexico: Charlas de Economia en mangas de camisa. Museo Interactivo de Economia: Mexico City. 
Heston, A., R. Summers and B. Aten (2009), Penn World Table Version 6.3, Center for International Comparisons of Production, Income and Prices at the University of Pennsylvania.

IDB (2004), Good Jobs Wanted: Labor Markets in Latin America, Inter-American Development Bank, Economic and Social Progress Report, Washington, DC.

ILO (2007), 2007 Labour Overview: Latin America and the Caribbean, International Labour Organization, Regional Office for Latin America and the Caribbean: Lima, Peru.

Iniguez-Montiel, A. J. (2011), "Income Distribution Dynamics and the Decline of Inequality in Mexico (1989-2006)", mimeo, University of Tsukuba: Japan.

Kakwani, N., B. Prakash and H. Son (2000), "Growth, Inequality, and Poverty: An Introduction", Asian Development Review, 18 (2): 1-21.

Kuznets, S. (1955), "Economic Growth and Income Inequality", American Economic Review, 45 (1): 1-28.

Levy and Walton (2009), "Equity, Competition, and Growth in Mexico: An Overview". In S. Levy and M. Walton (eds.), No Growth without Equity? Inequality, Interests, and Competition in Mexico, International Bank for Reconstruction and Development / The World Bank: Washington.

Lopez, J. H. (2006), "The Relative Roles of Growth and Inequality for Poverty Reduction". In G. E. Perry, O. S. Arias, J. H. Lopez, W. F. Maloney and L. Serven (eds.), Poverty Reduction and Growth: Virtuous and Vicious Circles, The World Bank, Washington.

and L. Serven (2006), “A Normal Relationship?: Poverty, Growth, and Inequality", mimeo, The World Bank.

Lustig, N. (1992), Mexico: The Remaking of an Economy. Brookings Institution: Washington DC. 
McKinley, T. and D. Alarcon (1995), "The Prevalence of Rural Poverty in Mexico", World Development, 23 (9): 1575-1585.

Mayer-Foulkes, D. (2008), "The Human Development Trap in Mexico", World Development, 36 (5): 775-796.

Nissanke, M. and E. Thorbecke (2006), "Channels and Policy Debate in the Globalization-Inequality-Poverty Nexus”, World Development, 34 (8), 1338-1360.

OECD (2009), "Pedal to the metal: Structural reforms to boost long-term growth and spur recovery from the crisis". In OECD Economic Surveys: Mexico, Chapter 4, Organisation for Economic Co-operation and Development, Paris.

Oxfam (2000), "Growth with Equity is Good for the Poor", Policy Paper, June.

Ravallion, M. (1997), "Can High-Inequality Developing Countries Escape Absolute Poverty", Economic Letters, 56: 51-57.

(2001), "Growth, Inequality and Poverty: Looking Beyond Averages", World Development, 29 (11): 1803-1815.

(2002), "On the Urbanization of Poverty", Journal of Development Economics, 68 (2): 435-442.

(2005), "Inequality is Bad for the Poor", mimeo, The World Bank.

(2007), "Economic Growth and Poverty Reduction: Do Poor Countries Need to Worry about Inequality?", 2020 Focus Brief on the World's Poor and Hungry People, Washington, DC: IFPRI.

Ravallion, M. and S. Chen (2003), "Measuring Pro-Poor Growth", Economic Letters, 78 (1): 93-99.

(2007), "China's (uneven) progress against poverty", Journal of 
Development Economics, 82: 1-42.

Ravallion, M. and G. Datt (2002), "Why has economic growth been more pro-poor in some states of India than others?", Journal of Development Economics, 68 (2): 381-400.

Ravallion, M. and M. Huppi (1991), "Measuring Changes in Poverty: A Methodological Case Study of Indonesia during an Adjustment Period", World Bank Economic Review, 5: 57-82.

Rueda-Peiro, I. (2009), La Creciente Desigualdad en Mexico, 1st edition, Universidad Nacional Autonoma de Mexico, Instituto de Investigaciones Economicas: Mexico City.

Samaniego, N. (2005), "El mundo del trabajo. Una estructura en terrenos movedizos", Economia UNAM (Universidad Nacional Autonoma de Mexico), 2 (4): January.

Szekely, M. (1995), "Poverty in Mexico during adjustment", Review of Income and Wealth, 41 (3): 331-348.

(1998), The Economics of Poverty, Inequality and Wealth Accumulation in Mexico. MacMillan: London.

(2005), "Pobreza y desigualdad en Mexico entre 1950 y el 2004", Serie: Documentos de Investigacion (July), SEDESOL: Mexico City.

Thorbecke, E. and C. Charumilind (2002), "Economic Inequality and Its Socioeconomic Impact", World Development, 30 (9): 1477-1495.

United Nations (2000), Millennium Declaration http://www.un.org/millennium/ declaration/ares552e.htm [accessed 24 December 2010].

van der Hoeven, R. (2008), "Income Inequality Revisited: Can one bring sense back into economic policy?", Inaugural Address as Professor of Employment and Development Economics delivered on September 18 at the Institute of 
Social Studies, Hague, Netherlands.

World Bank (2007), Mexico 2006-2012: Creating the Foundations for Equitable Growth. Report No. 39993-MX, PREM Unit, LAC Region. 


\begin{tabular}{|c|c|c|c|c|c|}
\hline \multicolumn{6}{|c|}{$\begin{array}{l}\text { TABLE 1: Descriptive Statistics on Distribution of the Population } \\
\text { by Education Level, Occupation and Location (1992-2008) }\end{array}$} \\
\hline & 1992 & 2008 & & 1992 & 2008 \\
\hline \multicolumn{3}{|l|}{ Educational Level } & \multicolumn{3}{|l|}{ Location } \\
\hline No Education & $45.8 \%$ & $30.9 \%$ & \multicolumn{3}{|l|}{ North Region } \\
\hline Primary & $22.9 \%$ & $22.3 \%$ & Chihuahua & $3.6 \%$ & $3.6 \%$ \\
\hline Middle & $13.1 \%$ & $22.6 \%$ & Coahuila & $2.7 \%$ & $2.6 \%$ \\
\hline Secondary & $10.8 \%$ & $16.4 \%$ & Durango & $1.6 \%$ & $1.4 \%$ \\
\hline \multirow[t]{2}{*}{ Tertiary } & $7.4 \%$ & $7.7 \%$ & San Luis Potosi & $2.4 \%$ & $2.3 \%$ \\
\hline & & & Zacatecas & $1.4 \%$ & $1.4 \%$ \\
\hline Occupation & & & \multicolumn{3}{|l|}{ Centre Region } \\
\hline Unemployed & $1.1 \%$ & $1.7 \%$ & Hidalgo & $2.4 \%$ & $2.2 \%$ \\
\hline Inactive & $13.3 \%$ & $19.6 \%$ & Mexico & $11.9 \%$ & $13.1 \%$ \\
\hline $\begin{array}{l}\text { Professional \&Technical } \\
\text { Workers, \& Professors }\end{array}$ & $7.0 \%$ & $7.7 \%$ & Morelos & $1.5 \%$ & $1.6 \%$ \\
\hline $\begin{array}{l}\text { Arts, Sports \& } \\
\text { Entertaintment Workers }\end{array}$ & $0.8 \%$ & $0.6 \%$ & Puebla & $4.3 \%$ & $4.8 \%$ \\
\hline $\begin{array}{l}\text { Public Servants } \\
\text { \& Firm Managers }\end{array}$ & $2.9 \%$ & $2.4 \%$ & Queretaro & $1.3 \%$ & $1.5 \%$ \\
\hline Agricultural Workers & $18.6 \%$ & $12.6 \%$ & Tlaxcala & $0.9 \%$ & $0.9 \%$ \\
\hline $\begin{array}{l}\text { Industrial Supervisors } \\
\text { \& Control Workers }\end{array}$ & $1.7 \%$ & $1.8 \%$ & \multicolumn{3}{|l|}{ Federal District } \\
\hline Industrial Workers & $17.8 \%$ & $15.7 \%$ & D.F. & $10.5 \%$ & $9.1 \%$ \\
\hline $\begin{array}{l}\text { Unskilled Industrial } \\
\text { Workers }\end{array}$ & $4.4 \%$ & $5.0 \%$ & \multicolumn{3}{|c|}{ Centre-West Region } \\
\hline Drivers & $5.9 \%$ & $5.4 \%$ & Aguascalientes & $0.8 \%$ & $1.0 \%$ \\
\hline Administrative Workers & $5.2 \%$ & $5.8 \%$ & Colima & $0.6 \%$ & $0.6 \%$ \\
\hline $\begin{array}{l}\text { Self-employed Workers } \\
\text { \& Sellers }\end{array}$ & $12.4 \%$ & $13.2 \%$ & Guanajuato & $4.4 \%$ & $4.3 \%$ \\
\hline Service Workers & $3.6 \%$ & $5.7 \%$ & Jalisco & $6.4 \%$ & $6.2 \%$ \\
\hline $\begin{array}{l}\text { Protection \& } \\
\text { Vigilant Workers }\end{array}$ & $2.4 \%$ & $2.6 \%$ & Michoacan & $4.3 \%$ & $3.7 \%$ \\
\hline \multirow[t]{2}{*}{ Other Workers } & $2.9 \%$ & $0.2 \%$ & \multicolumn{3}{|l|}{ South Region } \\
\hline & & & Tabasco & $1.8 \%$ & $1.9 \%$ \\
\hline \multicolumn{3}{|l|}{ Location } & Veracruz & $7.6 \%$ & $7.1 \%$ \\
\hline North-West Region & & & \multicolumn{3}{|c|}{ South-West Region } \\
\hline Baja California & $2.6 \%$ & $3.0 \%$ & Chiapas & $3.4 \%$ & $3.9 \%$ \\
\hline Baja California Sur & $0.4 \%$ & $0.6 \%$ & Guerrero & $3.1 \%$ & $2.7 \%$ \\
\hline Nayarit & $1.1 \%$ & $1.0 \%$ & Oaxaca & $3.4 \%$ & $3.2 \%$ \\
\hline Sinaloa & $2.8 \%$ & $2.5 \%$ & \multicolumn{3}{|c|}{ South-East Region } \\
\hline Sonora & $2.3 \%$ & $2.5 \%$ & Campeche & $0.7 \%$ & $0.7 \%$ \\
\hline North-East Region & & & Quintana Roo & $0.7 \%$ & $1.3 \%$ \\
\hline Nuevo Leon & $4.0 \%$ & $4.3 \%$ & Yucatan & $1.7 \%$ & $1.8 \%$ \\
\hline \multirow[t]{4}{*}{ Tamaulipas } & $3.2 \%$ & $3.3 \%$ & & & \\
\hline & & & \multicolumn{3}{|l|}{ Sector } \\
\hline & & & Rural & $23.5 \%$ & $20.7 \%$ \\
\hline & & & Urban & $76.6 \%$ & $79.3 \%$ \\
\hline
\end{tabular}


TABLE 2

Poverty (H) among households in Mexico by Educational Level (1992-2008)

\begin{tabular}{|lc|c|c|c|c|c|}
\hline & \multicolumn{2}{c|}{ Extreme Poverty } & \multicolumn{2}{c|}{ Moderate Poverty } & \multicolumn{2}{c}{ Overall Poverty } \\
\cline { 2 - 7 } No Education & $\mathbf{1 9 9 2}$ & $\mathbf{2 0 0 8}$ & $\mathbf{1 9 9 2}$ & $\mathbf{2 0 0 8}$ & $\mathbf{1 9 9 2}$ & $\mathbf{2 0 0 8}$ \\
\cline { 2 - 7 } Primary & $38.5 \%$ & $31.9 \%$ & $32.4 \%$ & $33.6 \%$ & $70.9 \%$ & $65.5 \%$ \\
Middle & $21.4 \%$ & $21.7 \%$ & $37.3 \%$ & $33.8 \%$ & $58.8 \%$ & $55.5 \%$ \\
Secondary & $9.2 \%$ & $15.4 \%$ & $30.9 \%$ & $33.6 \%$ & $40.1 \%$ & $49.1 \%$ \\
Tertiary & $2.2 \%$ & $5.4 \%$ & $15.4 \%$ & $18.1 \%$ & $17.5 \%$ & $23.5 \%$ \\
Total (National) & $0.3 \%$ & $0.9 \%$ & $4.4 \%$ & $7.7 \%$ & $4.7 \%$ & $8.6 \%$ \\
& $24 \%$ & $19 \%$ & $29 \%$ & $29 \%$ & $53 \%$ & $48 \%$
\end{tabular}

$H$ stands for the headcount index

Source: Own calculations based on the Household Income and Expenditure Surveys by INEGI. 


\begin{tabular}{|c|c|c|c|c|c|}
\hline \multicolumn{6}{|c|}{$\begin{array}{c}\text { TABLE } 3 \\
\text { Contribution to Overall Poverty by Education Level, Occupatio }\end{array}$} \\
\hline & 1992 & 2008 & & 1992 & 2008 \\
\hline \multicolumn{3}{|l|}{ Educational Level } & \multicolumn{3}{|l|}{ Location } \\
\hline No Education & $60.76 \%$ & $41.97 \%$ & \multicolumn{3}{|l|}{ North Region } \\
\hline Primary & $25.20 \%$ & $25.64 \%$ & Chihuahua & $2.3 \%$ & $2.8 \%$ \\
\hline Middle & $9.85 \%$ & $23.01 \%$ & Coahuila & $2.6 \%$ & $2.3 \%$ \\
\hline Secondary & $3.53 \%$ & $8.01 \%$ & Durango & $1.7 \%$ & $1.7 \%$ \\
\hline \multirow[t]{2}{*}{ Tertiary } & $0.66 \%$ & $1.37 \%$ & San Luis Potosi & $3.0 \%$ & $2.4 \%$ \\
\hline & & & Zacatecas & $1.8 \%$ & $1.4 \%$ \\
\hline Occupation & & & \multicolumn{3}{|l|}{ Centre Region } \\
\hline Unemployed & $0.8 \%$ & $2.2 \%$ & Hidalgo & $3.0 \%$ & $3.1 \%$ \\
\hline Inactive & $10.3 \%$ & $17.9 \%$ & Mexico & $10.9 \%$ & $13.8 \%$ \\
\hline $\begin{array}{l}\text { Professional \&Technical } \\
\text { Workers, \& Professors }\end{array}$ & $2.2 \%$ & $2.3 \%$ & Morelos & $1.6 \%$ & $1.5 \%$ \\
\hline $\begin{array}{l}\text { Arts, Sports \& } \\
\text { Entertaintment Workers }\end{array}$ & $0.6 \%$ & $0.4 \%$ & Puebla & $5.8 \%$ & $6.8 \%$ \\
\hline $\begin{array}{l}\text { Public Servants } \\
\text { \& Firm Managers }\end{array}$ & $0.3 \%$ & $0.3 \%$ & Queretaro & $1.3 \%$ & $1.4 \%$ \\
\hline Agricultural Workers & $29.7 \%$ & $21.1 \%$ & Tlaxcala & $1.3 \%$ & $1.2 \%$ \\
\hline $\begin{array}{l}\text { Industrial Supervisors } \\
\text { \& Control Workers }\end{array}$ & $0.6 \%$ & $0.8 \%$ & \multicolumn{3}{|l|}{ Federal District } \\
\hline Industrial Workers & $20.5 \%$ & $18.0 \%$ & D.F. & $6.2 \%$ & $5.2 \%$ \\
\hline $\begin{array}{l}\text { Unskilled Industrial } \\
\text { Workers }\end{array}$ & $6.6 \%$ & $7.3 \%$ & \multicolumn{3}{|c|}{ Centre-West Region } \\
\hline Drivers & $6.4 \%$ & $5.6 \%$ & Aguascalientes & $1.0 \%$ & $0.8 \%$ \\
\hline Administrative Workers & $2.0 \%$ & $2.9 \%$ & Colima & $0.4 \%$ & $0.4 \%$ \\
\hline $\begin{array}{l}\text { Self-employed Workers } \\
\text { \& Sellers }\end{array}$ & $10.9 \%$ & $12.9 \%$ & Guanajuato & $5.5 \%$ & $4.9 \%$ \\
\hline Service Workers & $3.6 \%$ & $5.8 \%$ & Jalisco & $5.4 \%$ & $5.4 \%$ \\
\hline $\begin{array}{l}\text { Protection \& } \\
\text { Vigilant Workers }\end{array}$ & $2.7 \%$ & $2.4 \%$ & Michoacan & $5.6 \%$ & $4.1 \%$ \\
\hline \multirow[t]{2}{*}{ Other Workers } & $2.8 \%$ & $0.2 \%$ & \multicolumn{3}{|l|}{ South Region } \\
\hline & & & Tabasco & $1.8 \%$ & $2.3 \%$ \\
\hline \multicolumn{3}{|l|}{ Location } & Veracruz & $8.7 \%$ & $8.2 \%$ \\
\hline North-West Region & & & \multicolumn{3}{|c|}{ South-West Region } \\
\hline Baja California & $1.2 \%$ & $1.9 \%$ & Chiapas & $5.3 \%$ & $6.3 \%$ \\
\hline Baja California Sur & $0.3 \%$ & $0.2 \%$ & Guerrero & $4.1 \%$ & $3.8 \%$ \\
\hline Nayarit & $1.2 \%$ & $1.1 \%$ & Oaxaca & $5.2 \%$ & $4.4 \%$ \\
\hline Sinaloa & $2.5 \%$ & $2.0 \%$ & \multicolumn{3}{|c|}{ South-East Region } \\
\hline Sonora & $1.5 \%$ & $1.8 \%$ & Campeche & $1.0 \%$ & $0.7 \%$ \\
\hline North-East Region & & & Quintana Roo & $0.5 \%$ & $0.9 \%$ \\
\hline Nuevo Leon & $2.6 \%$ & $2.2 \%$ & Yucatan & $2.2 \%$ & $2.0 \%$ \\
\hline \multirow[t]{4}{*}{ Tamaulipas } & $2.5 \%$ & $2.9 \%$ & & & \\
\hline & & & \multicolumn{3}{|l|}{ Sector } \\
\hline & & & Rural & $37.0 \%$ & $33.6 \%$ \\
\hline & & & Urban & $63.0 \%$ & $66.4 \%$ \\
\hline
\end{tabular}


TABLE 4

Poverty (H) among households in Mexico by Occupation (1992-2008)

\begin{tabular}{|c|c|c|c|c|c|c|}
\hline \multirow{2}{*}{ Occupation } & \multicolumn{2}{|c|}{ Extreme Poverty } & \multicolumn{2}{|c|}{ Moderate Poverty } & \multicolumn{2}{|c|}{ Overall Poverty } \\
\hline & 1992 & 2008 & 1992 & 2008 & 1992 & 2008 \\
\hline Unemployed & $18.0 \%$ & $27.6 \%$ & $22.7 \%$ & $33.1 \%$ & $40.8 \%$ & $60.7 \%$ \\
\hline Inactive & $13.7 \%$ & $16.5 \%$ & $27.6 \%$ & $27.5 \%$ & $41.3 \%$ & $44.0 \%$ \\
\hline $\begin{array}{l}\text { Professional \&Technical } \\
\text { Workers, \& Professors }\end{array}$ & $2.2 \%$ & $1.8 \%$ & $15.0 \%$ & $12.4 \%$ & $17.2 \%$ & $14.2 \%$ \\
\hline $\begin{array}{l}\text { Arts, Sports \& } \\
\text { Entertaintment Workers }\end{array}$ & $23.0 \%$ & $5.9 \%$ & $15.6 \%$ & $23.1 \%$ & $38.6 \%$ & $29.0 \%$ \\
\hline $\begin{array}{l}\text { Public Servants } \\
\text { \& Firm Managers }\end{array}$ & $0.7 \%$ & $1.3 \%$ & $4.1 \%$ & $3.8 \%$ & $4.9 \%$ & $5.0 \%$ \\
\hline Agricultural Workers & $60 \%$ & $55 \%$ & $24.9 \%$ & $26.1 \%$ & $85 \%$ & $81 \%$ \\
\hline $\begin{array}{l}\text { Industrial Supervisors } \\
\text { \& Control Workers }\end{array}$ & $3 \%$ & $2 \%$ & $15.0 \%$ & $20.8 \%$ & $18 \%$ & $23 \%$ \\
\hline Industrial Workers & $21 \%$ & $17 \%$ & $40.9 \%$ & $38.7 \%$ & $62 \%$ & $55 \%$ \\
\hline $\begin{array}{l}\text { Unskilled Industrial } \\
\text { Workers }\end{array}$ & $42 \%$ & $32 \%$ & $37.5 \%$ & $39.2 \%$ & $80 \%$ & $71 \%$ \\
\hline Drivers & $14 \%$ & $12 \%$ & $43.4 \%$ & $38.7 \%$ & $58 \%$ & $50 \%$ \\
\hline Administrative Workers & $5 \%$ & $4 \%$ & $16.0 \%$ & $19.4 \%$ & $21 \%$ & $24 \%$ \\
\hline $\begin{array}{l}\text { Self-employed Workers } \\
\text { \& Sellers }\end{array}$ & $15 \%$ & $16 \%$ & $31.7 \%$ & $31.0 \%$ & $47 \%$ & $47 \%$ \\
\hline Service Workers & $17 \%$ & $14 \%$ & $36.6 \%$ & $35.2 \%$ & $54 \%$ & $49 \%$ \\
\hline $\begin{array}{l}\text { Protection \& } \\
\text { Vigilant Workers }\end{array}$ & $19 \%$ & $9 \%$ & $40.7 \%$ & $35.8 \%$ & $60 \%$ & $45 \%$ \\
\hline Other Workers & $27 \%$ & $37 \%$ & $25.8 \%$ & $17.7 \%$ & $53 \%$ & $54 \%$ \\
\hline Total (National) & $24 \%$ & $19 \%$ & $29 \%$ & $29 \%$ & $53 \%$ & $48 \%$ \\
\hline
\end{tabular}




\section{TABLE 5}

Poverty (H) among households in Mexico by Location (1992-2008)

\begin{tabular}{|c|c|c|c|c|c|c|}
\hline & Extre & verty & Mode & overty & Ove & erty \\
\hline & 1992 & 2008 & 1992 & 2008 & 1992 & 2008 \\
\hline North-West Regio & & & & & & \\
\hline Baja California & $4.4 \%$ & $7.9 \%$ & $21.0 \%$ & $22.0 \%$ & $25.5 \%$ & $30.0 \%$ \\
\hline Baja California Sur & $8.3 \%$ & $4.6 \%$ & $31.3 \%$ & $17.1 \%$ & $39.6 \%$ & $21.7 \%$ \\
\hline Nayarit & $25.5 \%$ & $21.2 \%$ & $33.5 \%$ & $30.6 \%$ & $58.9 \%$ & $51.8 \%$ \\
\hline Sinaloa & $18.6 \%$ & $14.7 \%$ & $27.7 \%$ & $23.3 \%$ & $46.3 \%$ & $37.9 \%$ \\
\hline Sonora & $8.0 \%$ & $10.6 \%$ & $25.7 \%$ & $24.0 \%$ & $33.7 \%$ & $34.5 \%$ \\
\hline North-East Regio & & & & & & \\
\hline Nuevo Leon & $8.2 \%$ & $5.2 \%$ & $27.2 \%$ & $20.0 \%$ & $35.4 \%$ & $25.1 \%$ \\
\hline Tamaulipas & $11.0 \%$ & $10.6 \%$ & $31.5 \%$ & $31.0 \%$ & $42.5 \%$ & $41.5 \%$ \\
\hline North Region & & & & & & \\
\hline Chihuahua & $10.4 \%$ & $10.2 \%$ & $24.4 \%$ & $28.3 \%$ & $34.8 \%$ & $38.5 \%$ \\
\hline Coahuila & $22.7 \%$ & $11.4 \%$ & $29.9 \%$ & $31.8 \%$ & $52.6 \%$ & $43.3 \%$ \\
\hline Durango & $26.8 \%$ & $23.7 \%$ & $29.8 \%$ & $35.6 \%$ & $56.7 \%$ & $59.4 \%$ \\
\hline San Luis Potosi & $32.0 \%$ & $24.3 \%$ & $34.5 \%$ & $26.2 \%$ & $66.5 \%$ & $50.5 \%$ \\
\hline Zacatecas & $38.5 \%$ & $19.6 \%$ & $29.0 \%$ & $30.7 \%$ & $67.4 \%$ & $50.3 \%$ \\
\hline Centre Region & & & & & & \\
\hline Hidalgo & $39.9 \%$ & $32.8 \%$ & $28.3 \%$ & $35.6 \%$ & $68.2 \%$ & $68.5 \%$ \\
\hline Mexico & $15.0 \%$ & $16.4 \%$ & $34.0 \%$ & $34.5 \%$ & $48.9 \%$ & $50.8 \%$ \\
\hline Morelos & $24.1 \%$ & $12.7 \%$ & $32.2 \%$ & $31.1 \%$ & $56.3 \%$ & $43.8 \%$ \\
\hline Puebla & $51.8 \%$ & $29.7 \%$ & $20.0 \%$ & $38.8 \%$ & $71.8 \%$ & $68.5 \%$ \\
\hline Queretaro & $24.7 \%$ & $14.7 \%$ & $28.6 \%$ & $28.9 \%$ & $53.3 \%$ & $43.7 \%$ \\
\hline Tlaxcala & $45.8 \%$ & $24.1 \%$ & $32.0 \%$ & $37.6 \%$ & $77.9 \%$ & $61.7 \%$ \\
\hline Federal District & & & & & & \\
\hline D.F. & $5.5 \%$ & $5.6 \%$ & $25.7 \%$ & $22.2 \%$ & $31.2 \%$ & $27.8 \%$ \\
\hline Centre-West Regi & & & & & & \\
\hline Aguascalientes & $23.2 \%$ & $13.2 \%$ & $38.9 \%$ & $25.1 \%$ & $62.2 \%$ & $38.4 \%$ \\
\hline Colima & $12.4 \%$ & $8.6 \%$ & $26.6 \%$ & $24.9 \%$ & $39.0 \%$ & $33.4 \%$ \\
\hline Guanajuato & $31.8 \%$ & $21.5 \%$ & $34.5 \%$ & $34.3 \%$ & $66.3 \%$ & $55.8 \%$ \\
\hline Jalisco & $11.3 \%$ & $12.7 \%$ & $33.7 \%$ & $29.9 \%$ & $44.9 \%$ & $42.6 \%$ \\
\hline Michoacan & $33.8 \%$ & $23.7 \%$ & $35.6 \%$ & $29.6 \%$ & $69.4 \%$ & $53.3 \%$ \\
\hline South Region & & & & & & \\
\hline Tabasco & $35.5 \%$ & $25.4 \%$ & $17.8 \%$ & $33.4 \%$ & $53.2 \%$ & $58.8 \%$ \\
\hline Veracruz & $29.4 \%$ & $27.4 \%$ & $31.6 \%$ & $28.7 \%$ & $61.0 \%$ & $56.1 \%$ \\
\hline South-West Regic & & & & & & \\
\hline Chiapas & $54.5 \%$ & $56.1 \%$ & $28.6 \%$ & $21.3 \%$ & $83.0 \%$ & $77.4 \%$ \\
\hline Guerrero & $47.3 \%$ & $39.1 \%$ & $23.4 \%$ & $28.1 \%$ & $70.7 \%$ & $67.2 \%$ \\
\hline Oaxaca & $58.1 \%$ & $35.5 \%$ & $23.1 \%$ & $29.6 \%$ & $81.2 \%$ & $65.1 \%$ \\
\hline South-East Regio & & & & & & \\
\hline Campeche & $37.2 \%$ & $16.4 \%$ & $33.3 \%$ & $28.0 \%$ & $70.5 \%$ & $44.3 \%$ \\
\hline Quintana Roo & $11.8 \%$ & $14.0 \%$ & $28.0 \%$ & $21.9 \%$ & $39.8 \%$ & $36.0 \%$ \\
\hline Yucatan & $26.1 \%$ & $17.8 \%$ & $42.7 \%$ & $37.2 \%$ & $68.8 \%$ & $55.0 \%$ \\
\hline Total (National) & $24 \%$ & $19 \%$ & $29 \%$ & $29 \%$ & $53 \%$ & $48 \%$ \\
\hline
\end{tabular}


TABLE 6

Rural, urban and national poverty (H) in Mexico (1992-2008)

\begin{tabular}{|lc|c|c|c|c|c|}
\hline & \multicolumn{2}{c|}{ Extreme Poverty } & \multicolumn{2}{c|}{ Moderate Poverty } & \multicolumn{2}{c|}{ Overall Poverty } \\
& $\mathbf{1 9 9 2}$ & $\mathbf{2 0 0 8}$ & $\mathbf{1 9 9 2}$ & $\mathbf{2 0 0 8}$ & $\mathbf{1 9 9 2}$ & $\mathbf{2 0 0 8}$ \\
Rural & $57.0 \%$ & $46.7 \%$ & $27.2 \%$ & $31.8 \%$ & $84.2 \%$ & $78.5 \%$ \\
Urban & $13.9 \%$ & $12.0 \%$ & $30.1 \%$ & $28.4 \%$ & $44.0 \%$ & $40.4 \%$ \\
National & $24 \%$ & $19 \%$ & $29 \%$ & $29 \%$ & $53 \%$ & $48 \%$
\end{tabular}

$H$ stands for the headcount index

Source: Own calculations based on the Household Income and Expenditure Surveys by INEGI. 


\begin{tabular}{|c|c|c|c|c|c|c|c|c|c|c|c|c|c|}
\hline \multicolumn{14}{|c|}{$\begin{array}{l}\text { TABLE } 7 \\
\text { Poverty and Inequality in Mexico: Summary of Main Indicators (1992-2008) } \\
\end{array}$} \\
\hline & \multicolumn{3}{|c|}{$\begin{array}{l}\text { Relative Poverty } \\
\text { (Households) }\end{array}$} & \multicolumn{3}{|c|}{$\begin{array}{c}\text { Absolue Poverty } \\
\text { (Millions of Households) }\end{array}$} & \multicolumn{3}{|c|}{$\begin{array}{l}\text { Relative Poverty } \\
\text { (Persons) }\end{array}$} & \multicolumn{3}{|c|}{$\begin{array}{l}\text { Absolue Poverty } \\
\text { (Millions of Persons) }\end{array}$} & \multirow{2}{*}{$\begin{array}{l}\text { Inequality } \\
\text { Gini Indes }\end{array}$} \\
\hline & Extreme & Moderate & Overall & Extreme & Moderate & Overall & Extreme & Moderate & Overall & Extreme & Moderate & Overall & \\
\hline 1992 & $24.0 \%$ & $29.4 \%$ & $53.4 \%$ & 4.5 & 5.5 & 9.9 & $31.5 \%$ & $31.3 \%$ & $62.8 \%$ & 27.4 & 27.2 & 54.6 & $53.5 \%$ \\
\hline 1994 & $22.6 \%$ & $28.2 \%$ & $50.8 \%$ & 4.5 & 5.6 & 10.0 & $30.0 \%$ & $30.2 \%$ & $60.2 \%$ & 26.9 & 27.1 & 54.0 & $54.3 \%$ \\
\hline 1996 & $35.8 \%$ & $30.7 \%$ & $66.5 \%$ & 7.3 & 6.3 & 13.6 & $45.3 \%$ & $29.8 \%$ & $75.1 \%$ & 42.0 & 27.7 & 69.7 & $52.7 \%$ \\
\hline 1998 & $31.2 \%$ & $30.7 \%$ & $61.9 \%$ & 6.9 & 6.8 & 13.8 & $39.6 \%$ & $30.8 \%$ & $70.4 \%$ & 37.8 & 29.4 & 67.1 & $54.7 \%$ \\
\hline 2000 & $24.2 \%$ & $28.8 \%$ & $53.0 \%$ & 5.7 & 6.8 & 12.5 & $31.4 \%$ & $30.0 \%$ & $61.4 \%$ & 30.9 & 29.5 & 60.4 & $54.6 \%$ \\
\hline 2002 & $17.4 \%$ & $28.0 \%$ & $45.4 \%$ & 4.3 & 6.9 & 11.1 & $23.3 \%$ & $30.6 \%$ & $53.9 \%$ & 23.6 & 31.0 & 54.6 & $52.0 \%$ \\
\hline 2004 & $15.0 \%$ & $27.7 \%$ & $42.7 \%$ & 3.8 & 7.1 & 10.9 & $20.0 \%$ & $31.2 \%$ & $51.2 \%$ & 20.6 & 32.1 & 52.7 & $52.8 \%$ \\
\hline 2006 & $11.8 \%$ & $26.2 \%$ & $38.0 \%$ & 3.1 & 7.0 & 10.1 & $16.5 \%$ & $30.4 \%$ & $46.9 \%$ & 17.3 & 31.9 & 49.2 & $52.0 \%$ \\
\hline 2008 & $19.2 \%$ & $29.1 \%$ & $48.3 \%$ & 5.1 & 7.8 & 12.9 & $24.8 \%$ & $32.0 \%$ & $56.8 \%$ & 26.5 & 34.1 & 60.6 & $52.2 \%$ \\
\hline ource: & n calculatic & $s$ based on $t$ & Househol & come and & xpenditure $S$ & eys by IN & & & & & & & \\
\hline
\end{tabular}




\begin{tabular}{|c|c|c|c|c|c|c|c|c|c|c|c|c|c|c|c|c|c|c|c|c|}
\hline \multicolumn{21}{|c|}{$\begin{array}{l}\text { TABLE 8: Decomposition of Changes in National Poverty in Mexico into its Growth and Distribution Components } \\
\text { (\% point change in the FGT index) }\end{array}$} \\
\hline \multirow[b]{2}{*}{ Effect } & \multicolumn{4}{|c|}{$\underline{1992.2008}$} & \multicolumn{4}{|c|}{$\underline{1992-1996}$} & \multicolumn{4}{|c|}{$1996-2000$} & \multicolumn{4}{|c|}{$2000-2004$} & \multicolumn{4}{|c|}{$2004-2008$} \\
\hline & $\begin{array}{l}\text { Food } \\
\text { Poverty }\end{array}$ & $\begin{array}{c}\text { Capacities } \\
\text { Poverty }\end{array}$ & \begin{tabular}{|l|} 
Basic- \\
Needs \\
Poverty \\
\end{tabular} & \begin{tabular}{|l} 
Overall \\
Poverty
\end{tabular} & \begin{tabular}{|c|} 
Food \\
Poverty
\end{tabular} & $\begin{array}{c}\text { Capacities } \\
\text { Poverty }\end{array}$ & \begin{tabular}{l|} 
Basic- \\
Needs \\
Poverty \\
\end{tabular} & $\begin{array}{l}\text { Overall } \\
\text { Poverty }\end{array}$ & $\begin{array}{l}\text { Food } \\
\text { Poverty }\end{array}$ & $\begin{array}{c}\text { Capacities } \\
\text { Poverty }\end{array}$ & \begin{tabular}{|l|} 
Basic- \\
Needs \\
Poverty \\
\end{tabular} & $\begin{array}{l}\text { Overall } \\
\text { Poverty }\end{array}$ & $\begin{array}{c}\text { Food } \\
\text { Poverty }\end{array}$ & $\begin{array}{c}\text { Capacities } \\
\text { Poverty }\end{array}$ & \begin{tabular}{c|} 
Basic- \\
Needs \\
Poverty \\
\end{tabular} & $\begin{array}{l}\text { Overall } \\
\text { Poverty }\end{array}$ & $\begin{array}{c}\text { Food } \\
\text { Poverty }\end{array}$ & $\begin{array}{c}\text { Capacities } \\
\text { Poverty }\end{array}$ & \begin{tabular}{|c|} 
Basic- \\
Needs \\
Poverty \\
\end{tabular} & $\begin{array}{l}\text { Overall } \\
\text { Poverty }\end{array}$ \\
\hline Growth & -0.79 & -1.17 & -2.17 & -2.61 & 2.32 & 3.12 & 5.12 & 5.95 & -2.1 & -3.04 & -5.38 & -6.32 & -0.98 & -1.52 & -2.93 & -3.54 & 0.18 & 0.34 & 0.8 & 1.02 \\
\hline (contribution) & $56 \%$ & $55 \%$ & $57 \%$ & $59 \%$ & $190 \%$ & $165 \%$ & $131 \%$ & $122 \%$ & $145 \%$ & $144 \%$ & $137 \%$ & $134 \%$ & $71 \%$ & $68 \%$ & $66 \%$ & $66 \%$ & $86 \%$ & $97 \%$ & $123 \%$ & $134 \%$ \\
\hline Distribution & -0.82 & -1.15 & -1.78 & -1.90 & -0.81 & -1.05 & -1.27 & -1.22 & 1.01 & 1.25 & 1.61 & 1.66 & -0.67 & -1.02 & -1.73 & -1.94 & 0.03 & 0.02 & -0.13 & -0.24 \\
\hline (contribution) & $58 \%$ & $54 \%$ & $47 \%$ & $43 \%$ & $-66 \%$ & $.56 \%$ & $-32 \%$ & $-25 \%$ & $.70 \%$ & $-59 \%$ & $-41 \%$ & $-35 \%$ & $48 \%$ & $45 \%$ & $39 \%$ & $36 \%$ & $14 \%$ & $6 \%$ & $-20 \%$ & $-32 \%$ \\
\hline Residual & 0.20 & 0.20 & 0.13 & 0.06 & -0.29 & -0.18 & 0.06 & 0.13 & -0.36 & -0.32 & -0.16 & -0.07 & 0.26 & 0.29 & 0.21 & 0.14 & 0.00 & -0.01 & -0.02 & -0.02 \\
\hline (contribution) & $-14 \%$ & $-9 \%$ & $-4 \%$ & $-2 \%$ & $-24 \%$ & $-9 \%$ & $1 \%$ & $3 \%$ & $25 \%$ & $15 \%$ & $4 \%$ & $1 \%$ & $-19 \%$ & $-13 \%$ & $-5 \%$ & $-2 \%$ & $0 \%$ & $-3 \%$ & $-3 \%$ & $-2 \%$ \\
\hline Total change & -1.41 & -2.12 & -3.82 & -4.45 & 1.22 & 1.89 & 3.91 & 4.86 & -1.45 & -2.11 & -3.93 & -4.73 & -1.39 & -2.25 & -4.45 & -5.34 & 0.21 & 0.35 & 0.65 & 0.76 \\
\hline Note: The & 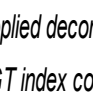 & inn & & & & on 1 & the & fo & & & & & & & & & & & & \\
\hline
\end{tabular}




\begin{tabular}{|c|c|c|c|c|c|c|c|c|c|c|}
\hline \multicolumn{7}{|c|}{ TABLE 9: Sectoral Decomposition of the Change in Poverty in Mexico } \\
(\% point change in the FGT index)
\end{tabular}




\begin{tabular}{|c|c|c|c|c|c|c|c|c|c|}
\hline \multicolumn{10}{|c|}{ TABLE 10: "National, Rural and Urban Growth Rates" } \\
\hline & \multicolumn{3}{|c|}{ National } & \multicolumn{3}{|c|}{$\underline{\text { Rural }}$} & \multicolumn{3}{|c|}{ Urban } \\
\hline & 1992-2008 & $1992-2000$ & 2000-2008 & 1992-2008 & $1992-2000$ & $2000-2008$ & 1992-2008 & 1992-2000 & $2000-2008$ \\
\hline & \multicolumn{3}{|c|}{ Growth rate in the mean income } & \multicolumn{3}{|c|}{ Growth rate in the mean income } & \multicolumn{3}{|c|}{ Growth rate in the mean income } \\
\hline & $13.3 \%$ & $1.1 \%$ & $12.1 \%$ & $26.5 \%$ & $-0.1 \%$ & $26.6 \%$ & $9.5 \%$ & $0.7 \%$ & $8.8 \%$ \\
\hline$p$ & \multicolumn{3}{|c|}{$\begin{array}{l}\text { Rate of pro-poor growth } \\
\text { for the poorest } p \%\end{array}$} & \multicolumn{3}{|c|}{$\begin{array}{l}\text { Rate of pro-poor growth } \\
\text { for the poorest } p \%\end{array}$} & \multicolumn{3}{|c|}{$\begin{array}{l}\text { Rate of pro-poor growth } \\
\text { for the poorest } p \%\end{array}$} \\
\hline 10 & $25.0 \%$ & $-5.6 \%$ & $32.5 \%$ & $25.4 \%$ & $-9.7 \%$ & $38.9 \%$ & $8.8 \%$ & $-2.0 \%$ & $11.0 \%$ \\
\hline 20 & $23.7 \%$ & $-4.2 \%$ & $29.3 \%$ & $28.2 \%$ & $-7.9 \%$ & $39.3 \%$ & $11.1 \%$ & $-1.5 \%$ & $12.7 \%$ \\
\hline 30 & $23.0 \%$ & $-3.2 \%$ & $27.1 \%$ & $28.6 \%$ & $-7.3 \%$ & $38.8 \%$ & $12.2 \%$ & $-1.0 \%$ & $13.3 \%$ \\
\hline 40 & $22.5 \%$ & $-2.2 \%$ & $25.4 \%$ & $28.7 \%$ & $-7.5 \%$ & $39.1 \%$ & $12.5 \%$ & $-0.8 \%$ & $13.4 \%$ \\
\hline
\end{tabular}

\begin{tabular}{|c|c|c|c|c|c|c|c|c|c|}
\hline \multicolumn{10}{|c|}{$\begin{array}{l}\text { TABLE 11 } \\
\text { Eradicating Extreme Poverty in Mexico }\end{array}$} \\
\hline \multirow[b]{2}{*}{ Sector } & \multirow[b]{2}{*}{$P^{*}$} & \multirow[b]{2}{*}{$z$} & \multirow[b]{2}{*}{$\mu^{*}$} & \multicolumn{4}{|c|}{ Years to Eradicate Poverty } & \multicolumn{2}{|c|}{ Required Growth Rate } \\
\hline & & & & $t(0.01)$ & $t(0.03)$ & $t(0.05)$ & $t(0.07)$ & $g(10)$ & $g(20)$ \\
\hline National & 0 & 1,149 & 8,121 & 70.4 & 23.7 & 14.4 & 10.4 & $7.26 \%$ & $3.57 \%$ \\
\hline Rural & 0 & 876 & 5,727 & 114.7 & 38.6 & 23.4 & 16.9 & $12.09 \%$ & $5.87 \%$ \\
\hline Urban & 0 & 1,221 & 6,964 & 41.6 & 14.0 & 8.5 & 6.1 & $4.23 \%$ & $2.09 \%$ \\
\hline \multicolumn{10}{|c|}{$\begin{array}{c}P^{*}=\text { poverty goal; } Z=\text { poverty line; } \mu^{*}=\text { income needed to meet poverty goal; } t(\delta)=\text { number of years in which the poverty } \\
\text { goal would be met if annual growth rate were } \delta ; g(t)=\text { minimum income growth rate necessary to eradicate poverty in t years. }\end{array}$} \\
\hline
\end{tabular}

\begin{tabular}{|c|c|c|c|c|c|c|c|c|c|}
\hline \multicolumn{10}{|c|}{$\begin{array}{l}\text { TABLE } 12 \\
\text { ng Overall Poverty in Mexico }\end{array}$} \\
\hline \multirow[b]{2}{*}{ Sector } & \multirow[b]{2}{*}{$P^{*}$} & \multirow[b]{2}{*}{$z$} & \multirow[b]{2}{*}{$\mu^{*}$} & \multicolumn{4}{|c|}{ Years to Eradicate Poverty } & \multicolumn{2}{|c|}{ Required Growth Rate } \\
\hline & & & & $t(0.01)$ & $t(0.03)$ & $t(0.05)$ & $t(0.07)$ & $g(25)$ & $g(50)$ \\
\hline National & 0 & 2,318 & 16,377 & 140.9 & 47.4 & 28.7 & 20.7 & $5.77 \%$ & $2.84 \%$ \\
\hline Rural & 0 & 1,674 & 10,947 & 179.8 & 60.5 & 36.7 & 26.4 & $7.42 \%$ & $3.64 \%$ \\
\hline Urban & 0 & 2,486 & 14,181 & 113.1 & 38.1 & 23.1 & 16.6 & $4.60 \%$ & $2.28 \%$ \\
\hline \multicolumn{10}{|c|}{$\begin{array}{l}P^{*}=\text { poverty goal; } Z=\text { poverty line; } \mu^{*}=\text { income needed to meet poverty goal; } t(\delta)=\text { number of years in which the poverty } \\
\text { goal would be met if annual growth rate were } \delta ; g(t)=\text { minimum income growth rate necessary to eradicate poverty in t years. }\end{array}$} \\
\hline
\end{tabular}




\section{FIGURE 1}
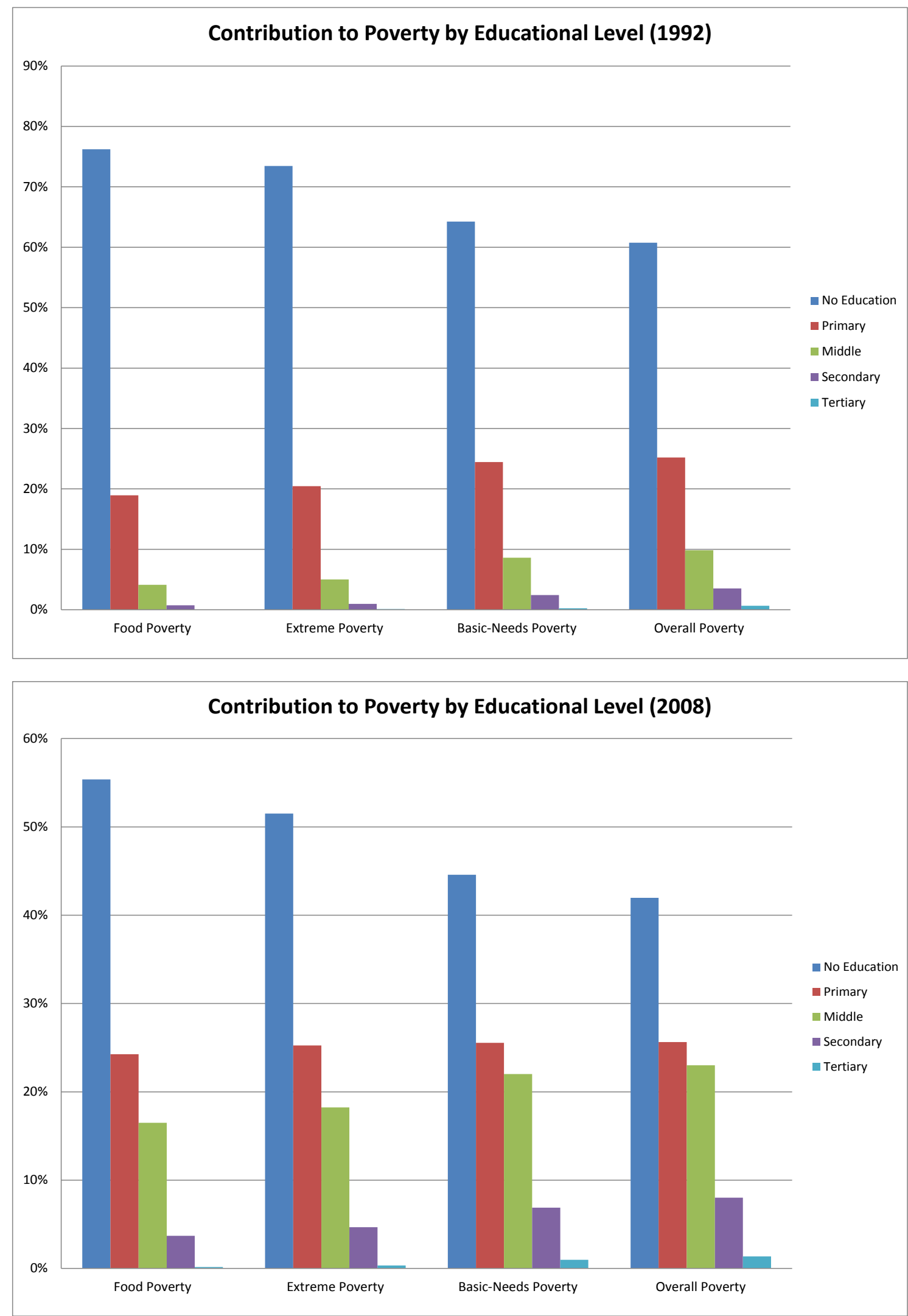


\section{FIGURE 2}
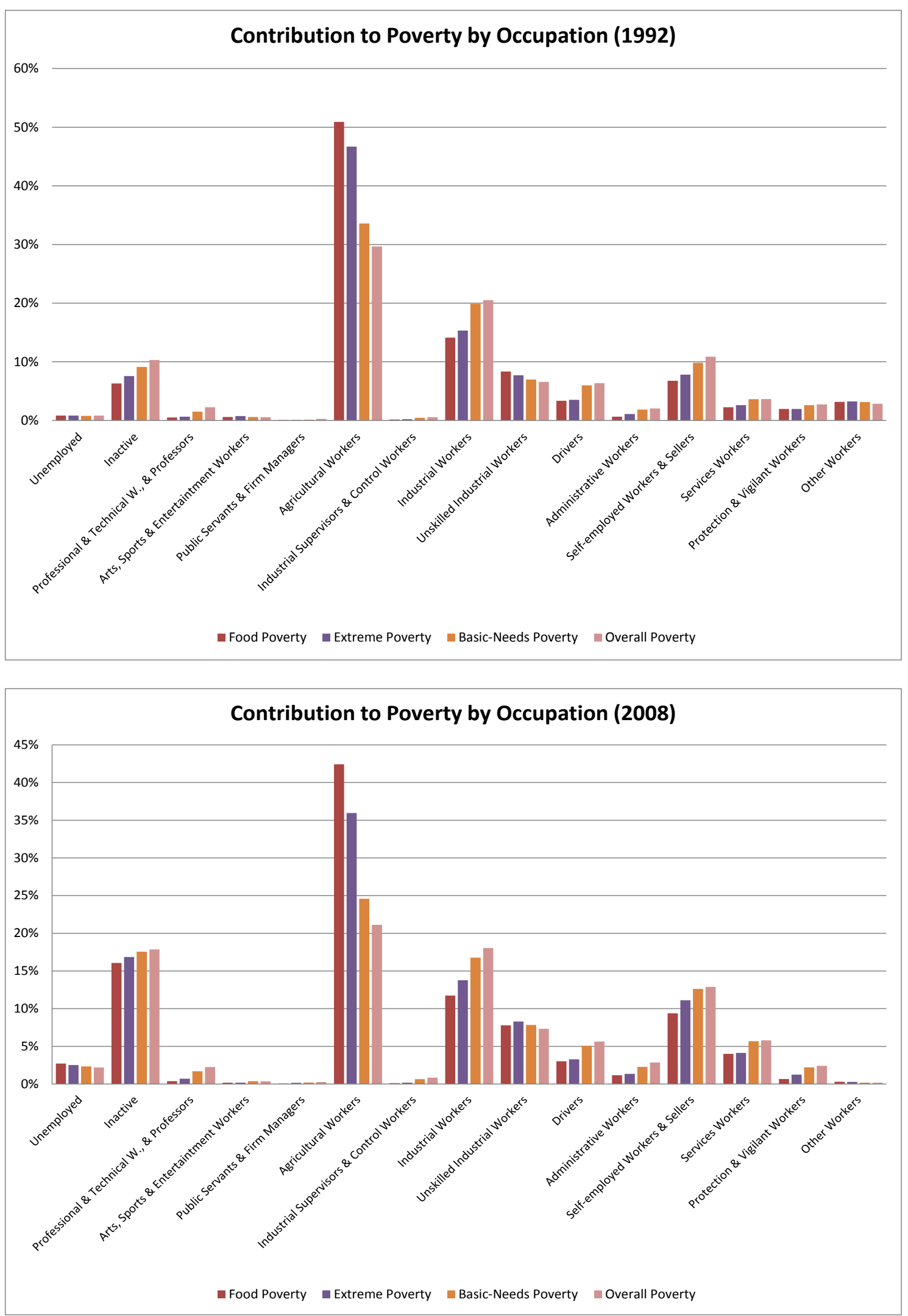


\section{FIGURE 3}

\section{GRAPH 1}

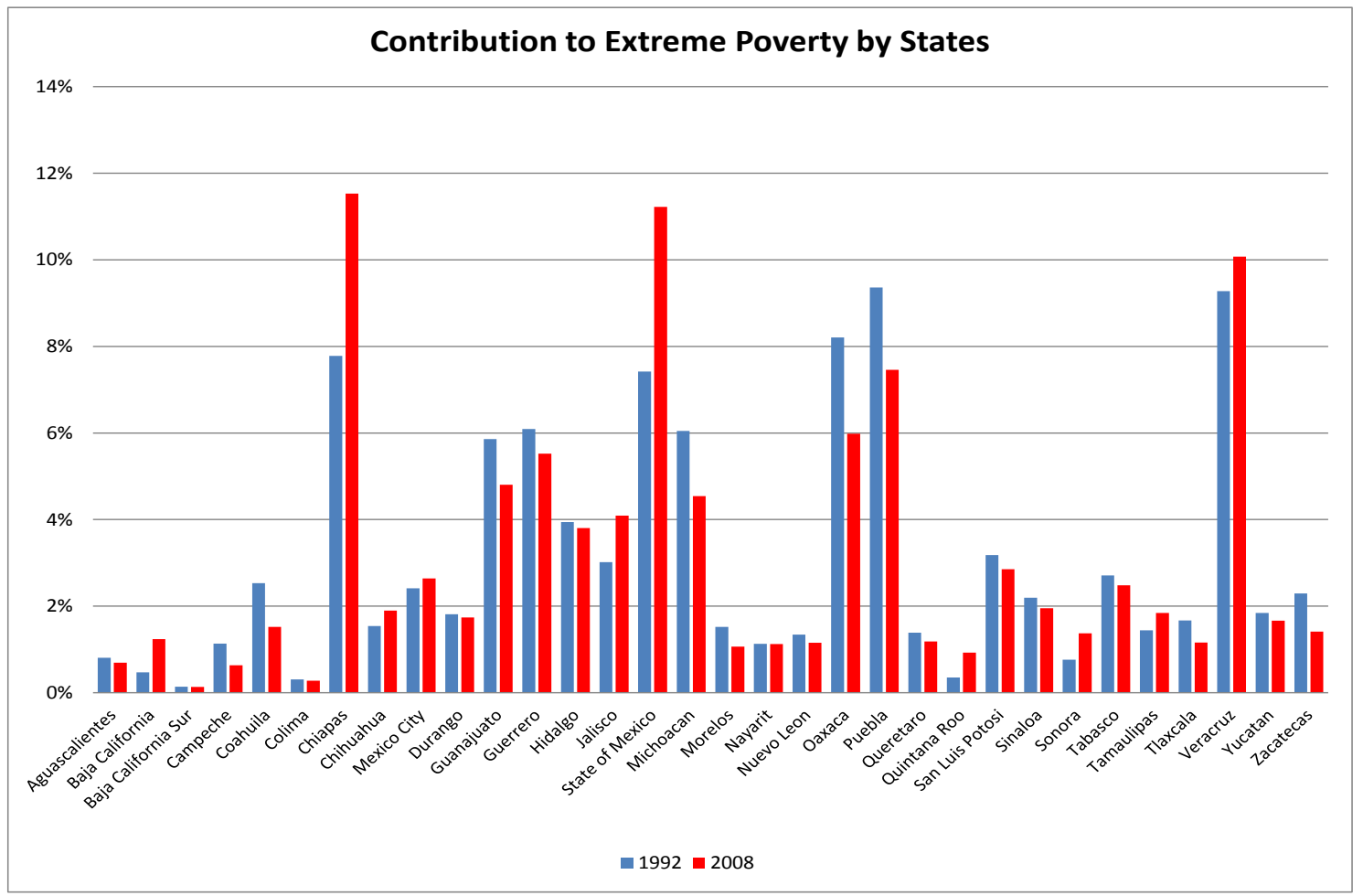

\section{GRAPH 2}

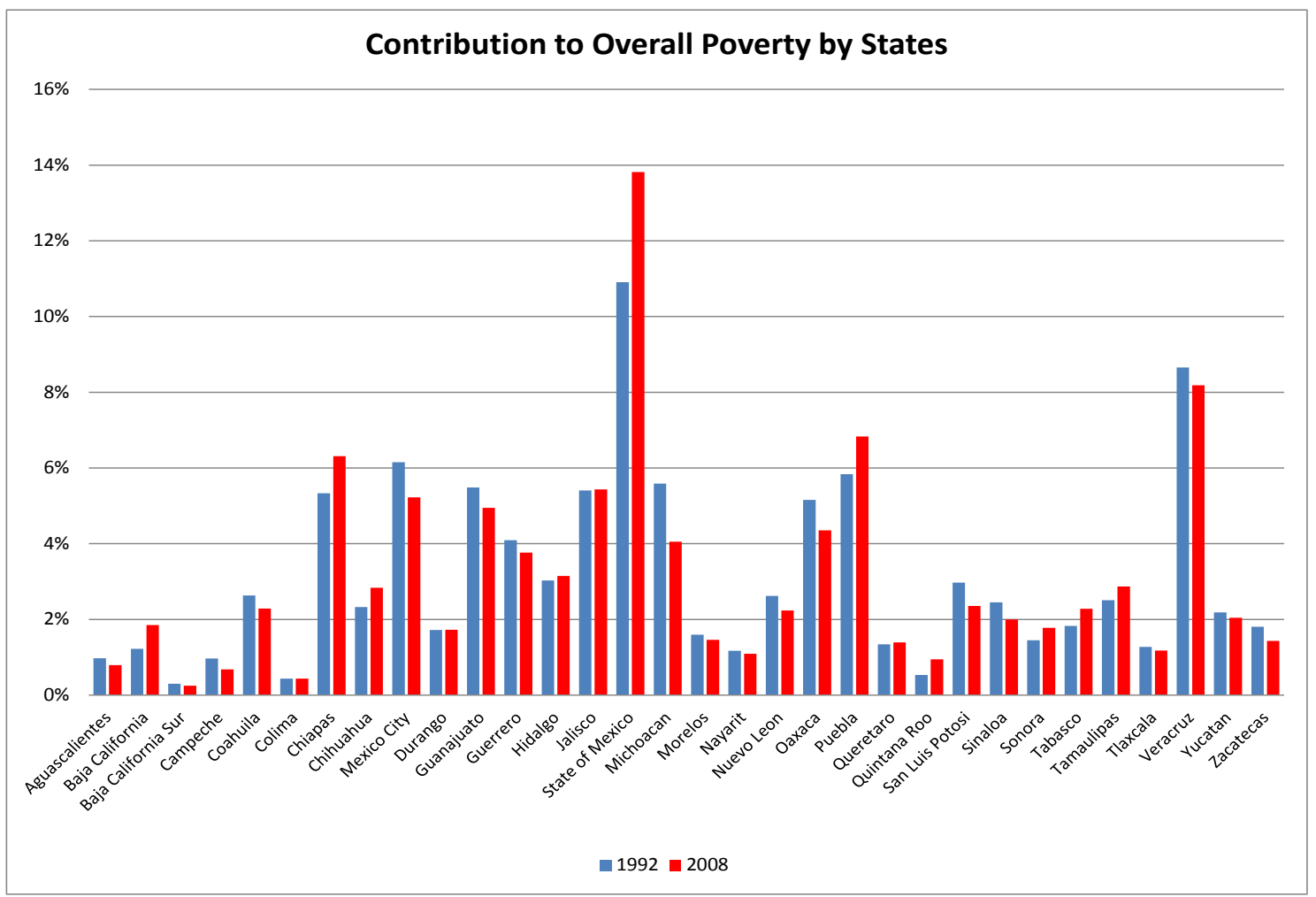




\section{FIGURE 4}

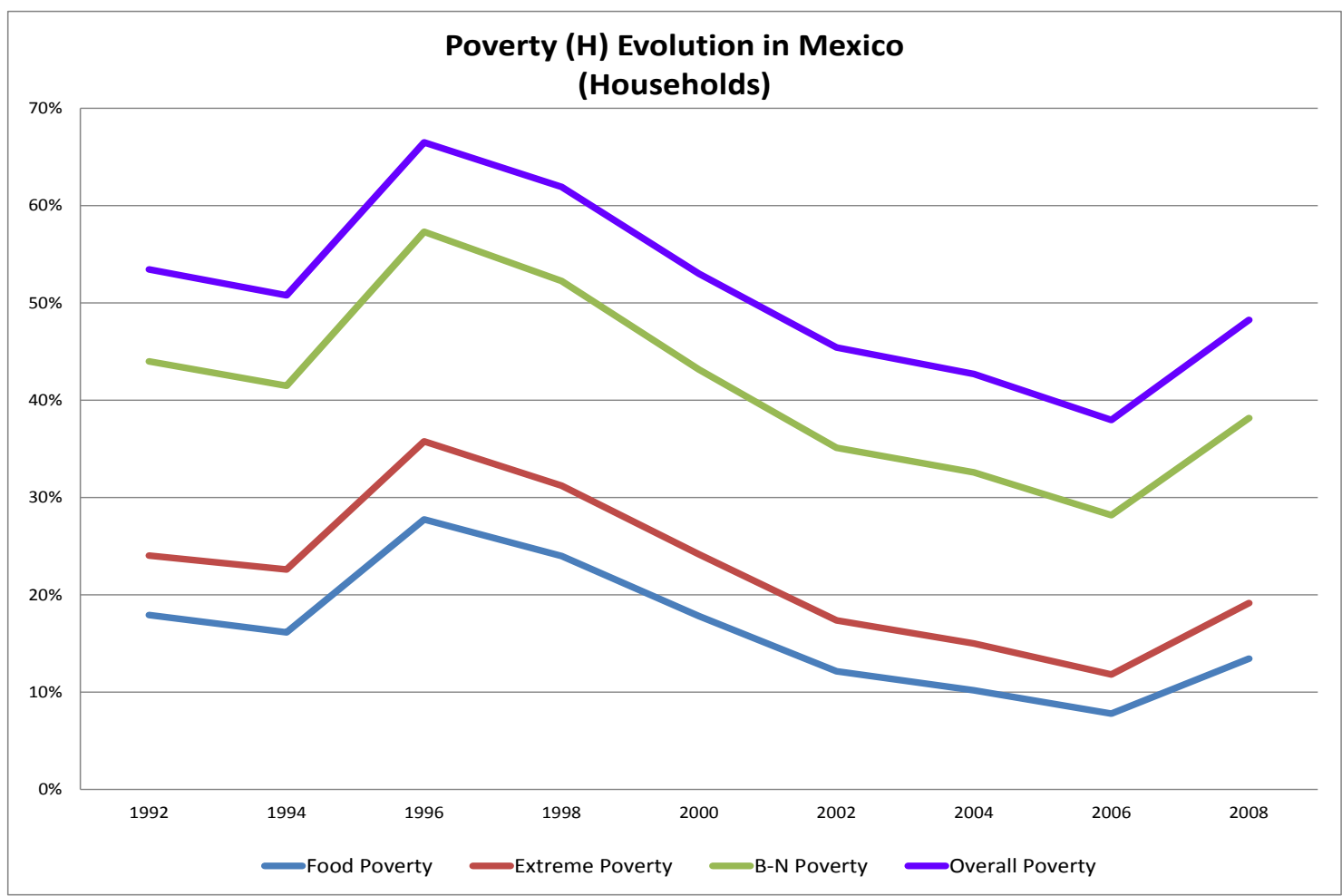

Note: $\mathrm{H}$ stands for the headcount index

\section{FIGURE 5}

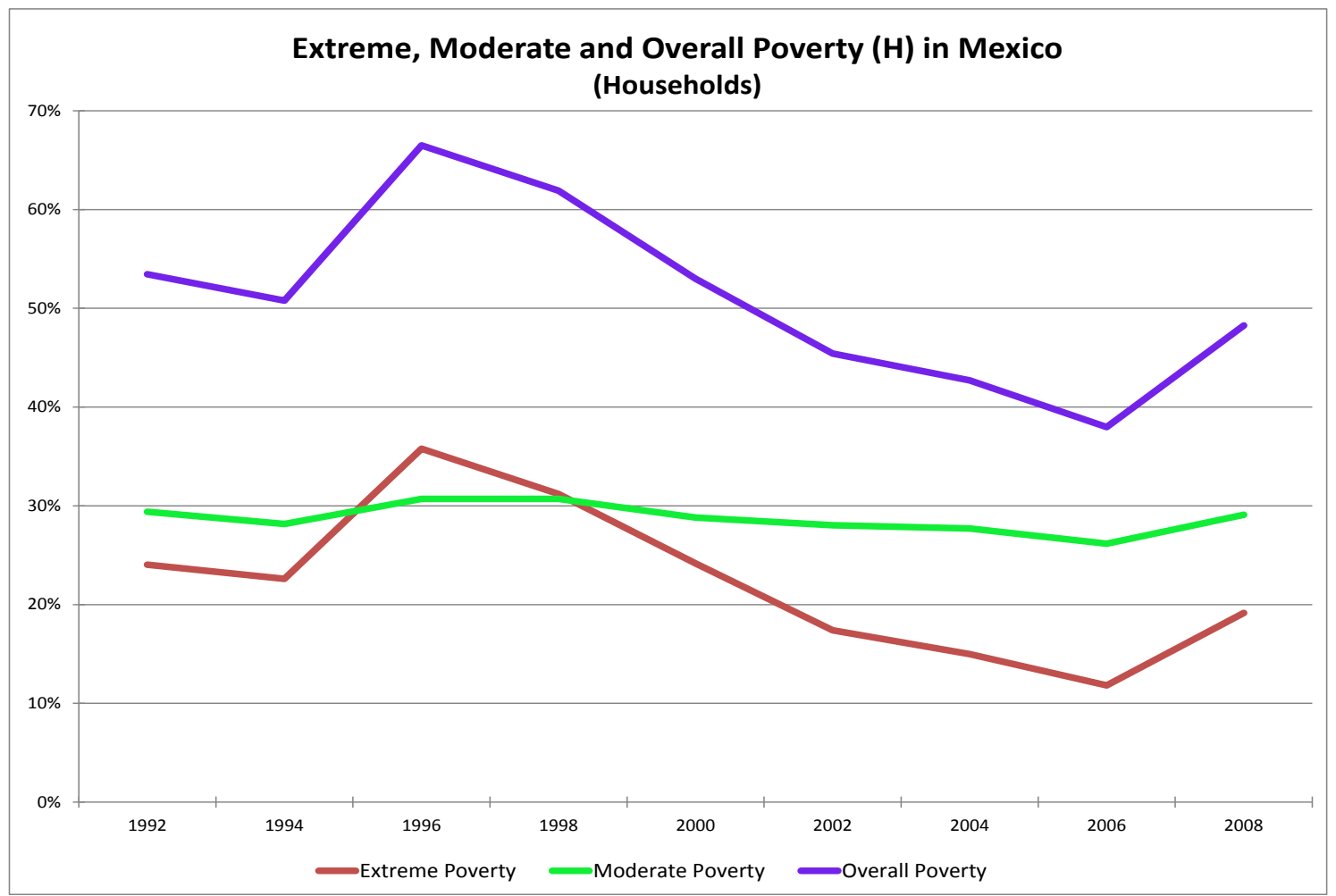

Note: $\mathrm{H}$ stands for the headcount index 


\section{FIGURE 6}

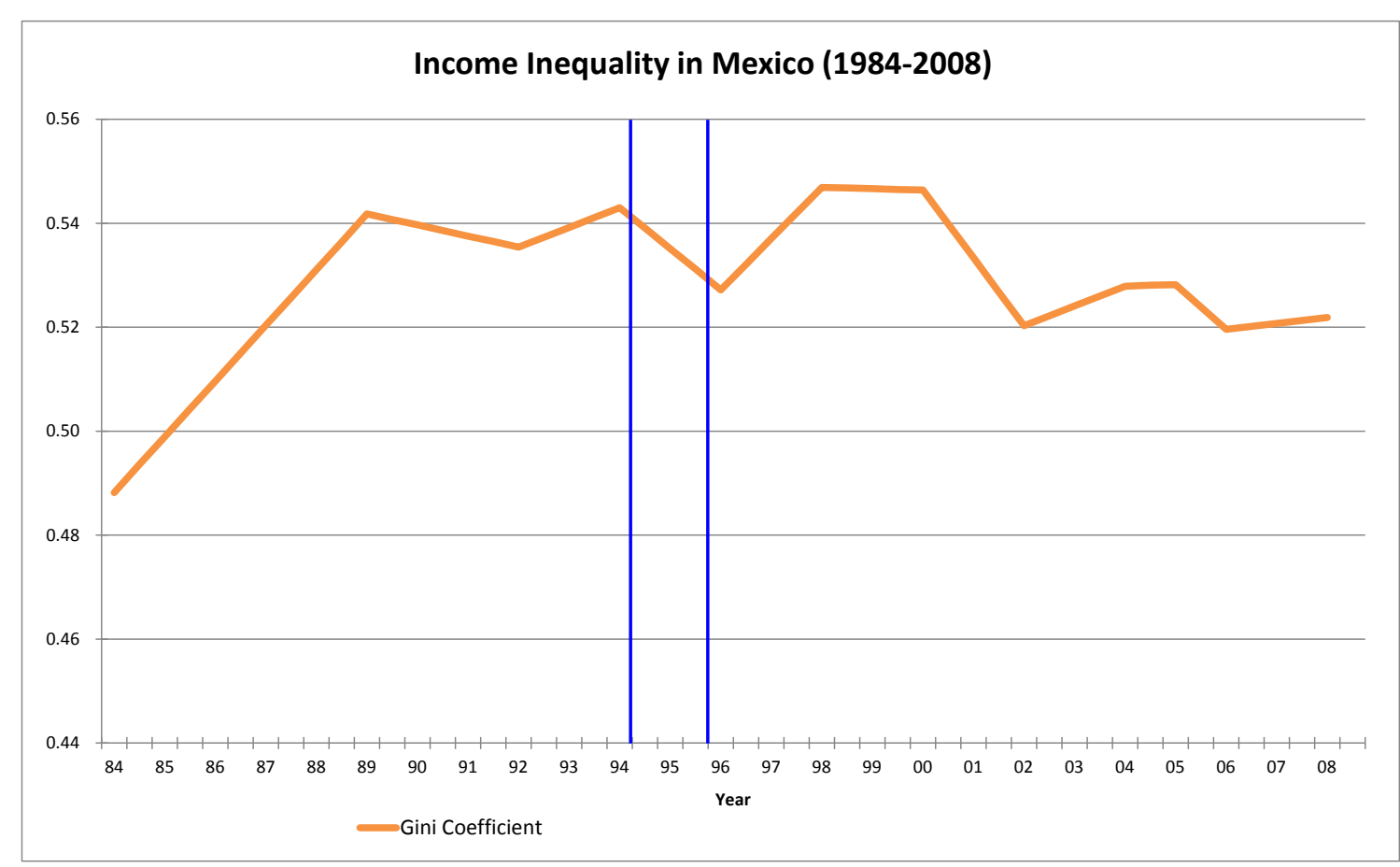

Source: Iniguez-Montiel (2011).

1994-1995 financial crisis

\section{FIGURE 7}

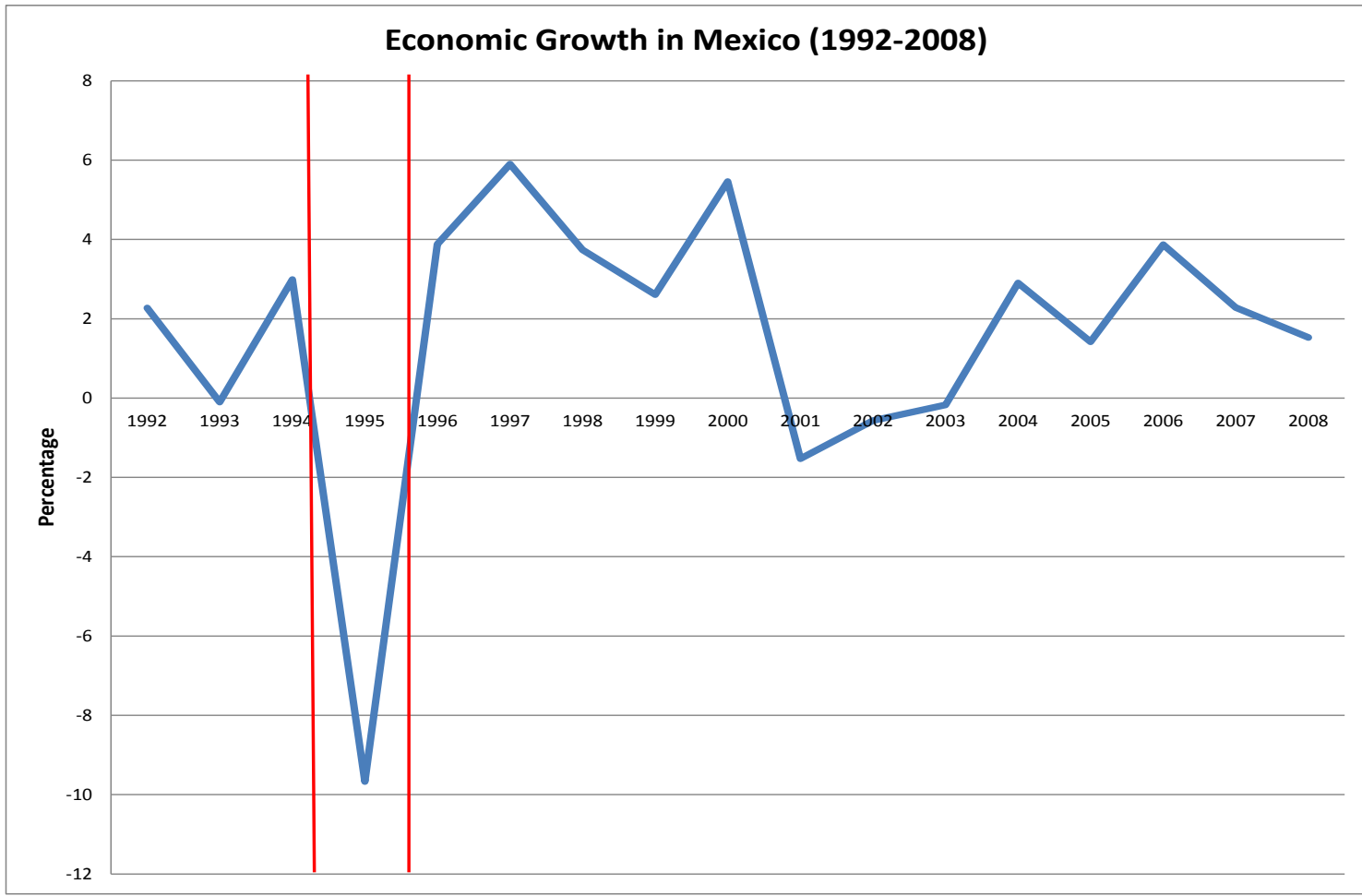

Source: Heston et al. (2009) and INEGl's 2008 macroeconomic indicator.

1994-1995 financial crisis 


\section{FigURE 8}

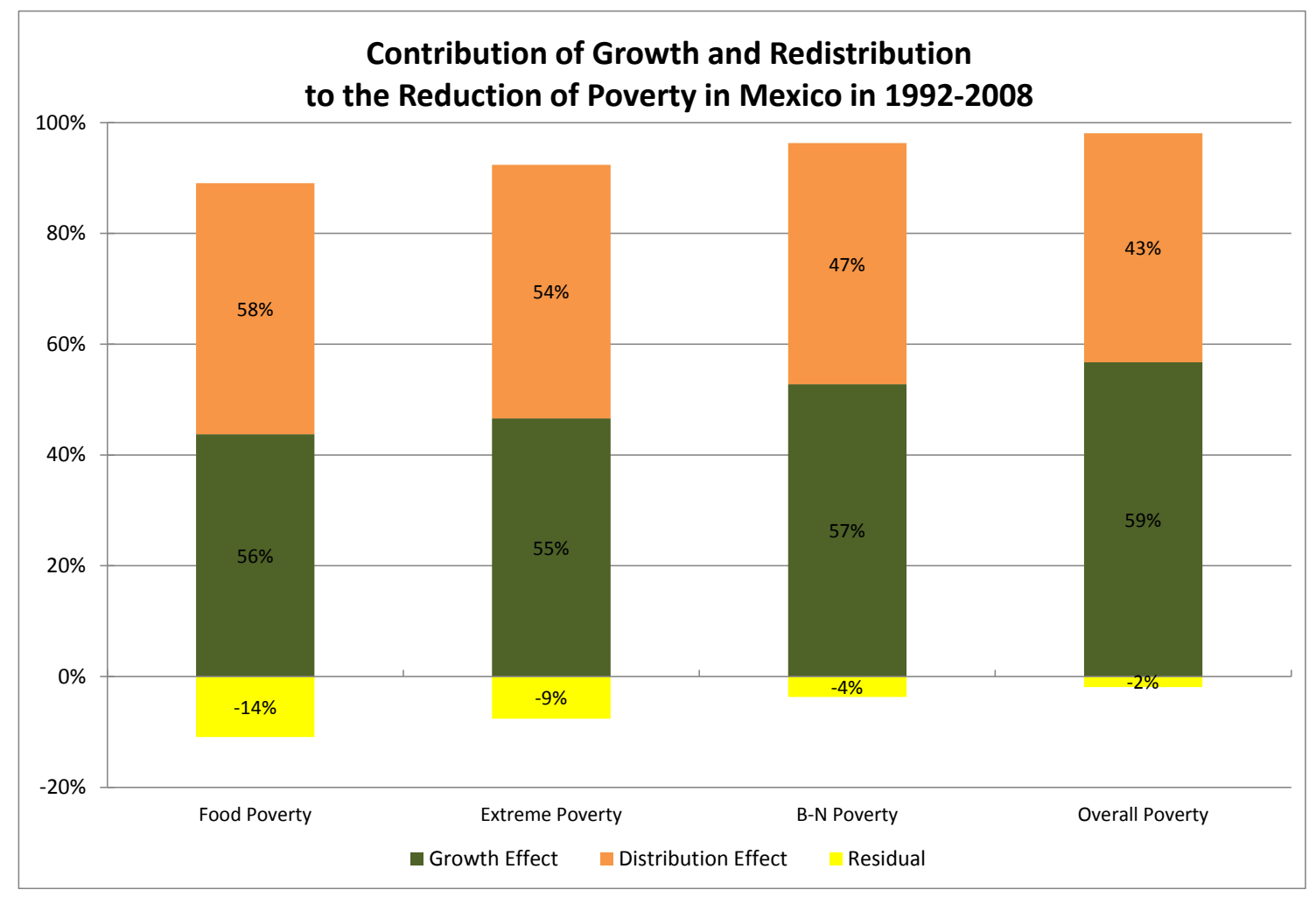

FIGURE 9

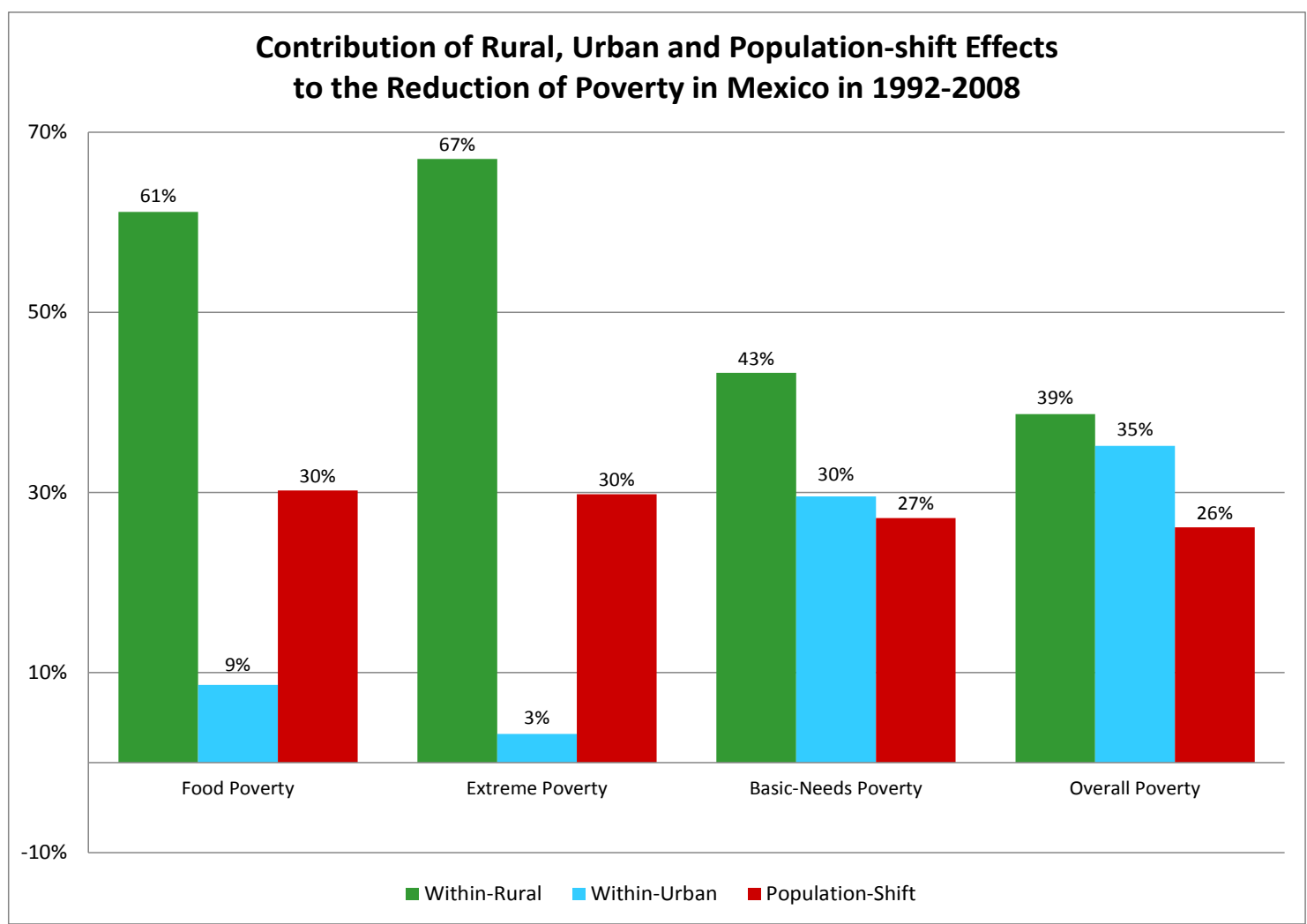


FIGURE 10

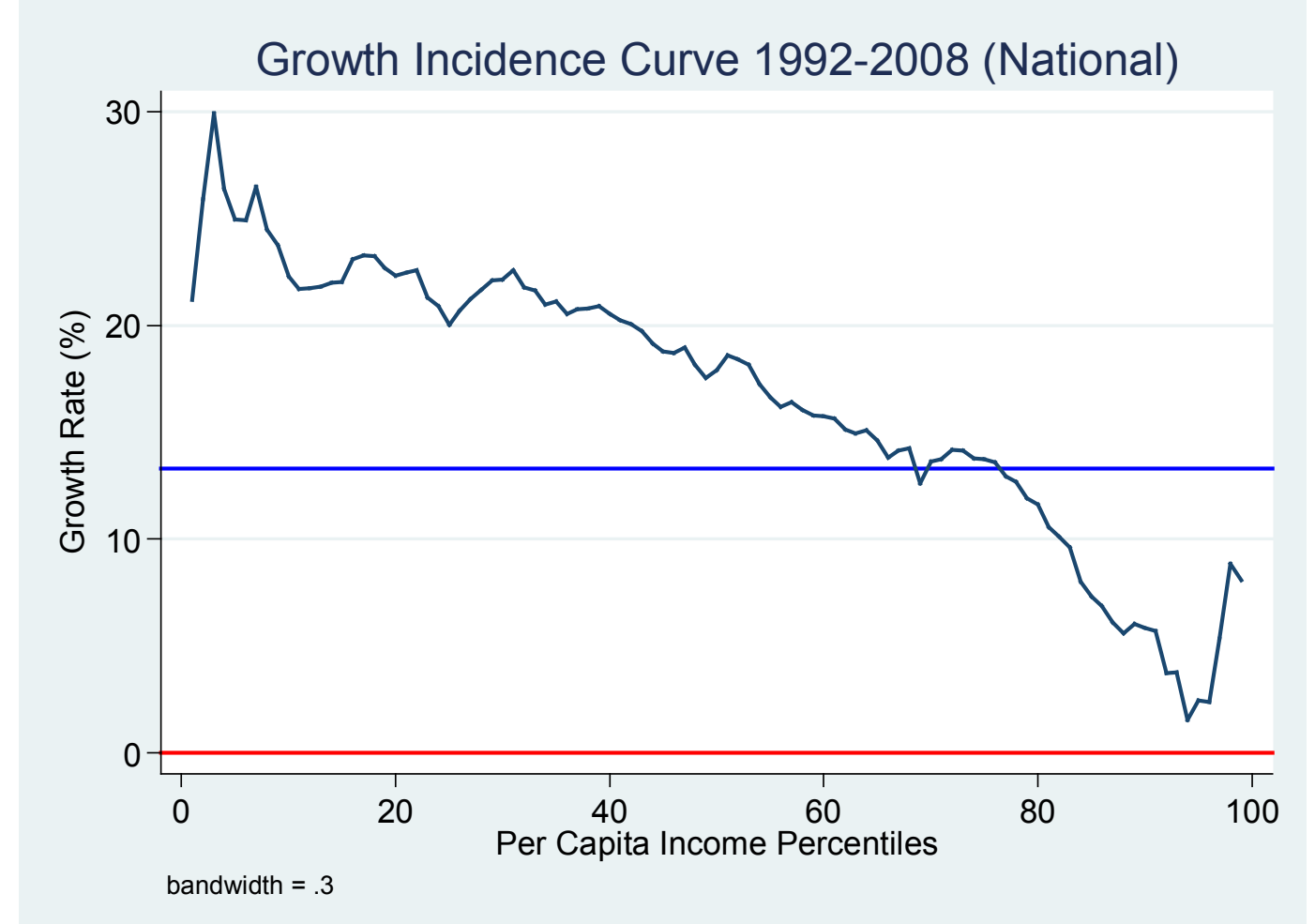

Growth incidence curve: actual and smoothed 


\section{FIGURE 11}
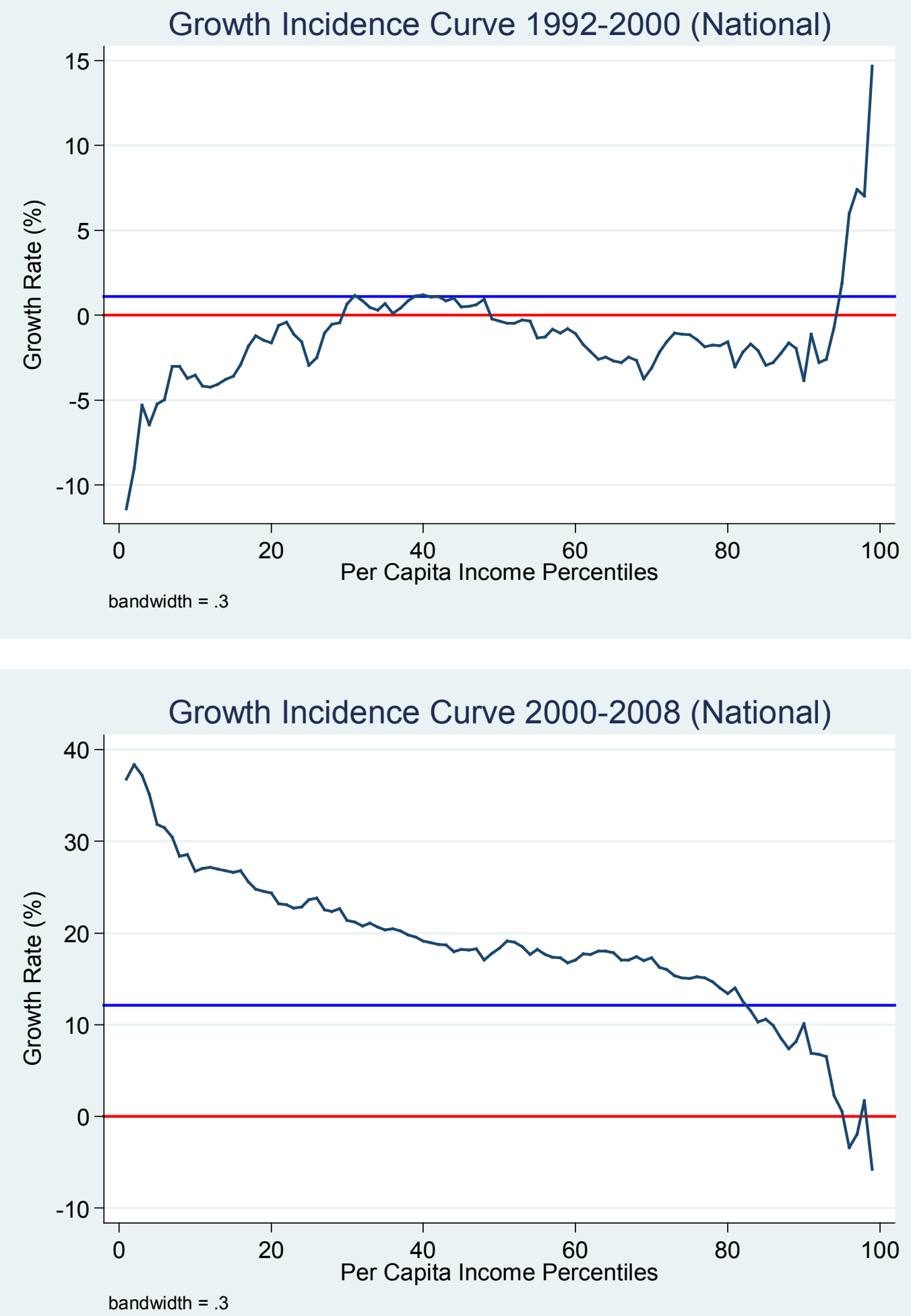

Growth incidence curve: actual and smoothed 
FIGURE 12

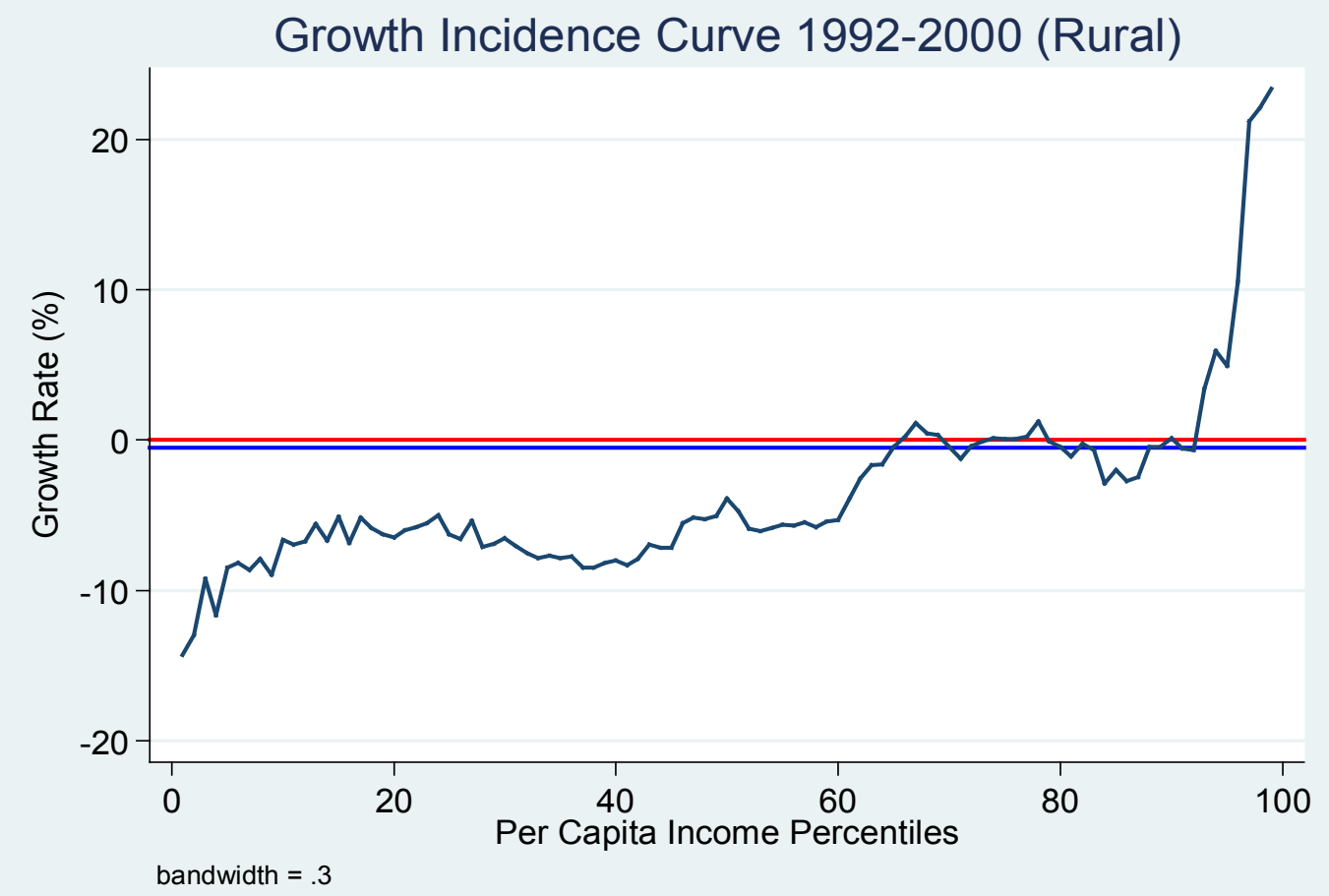

Growth Incidence Curve 2000-2008 (Rural)

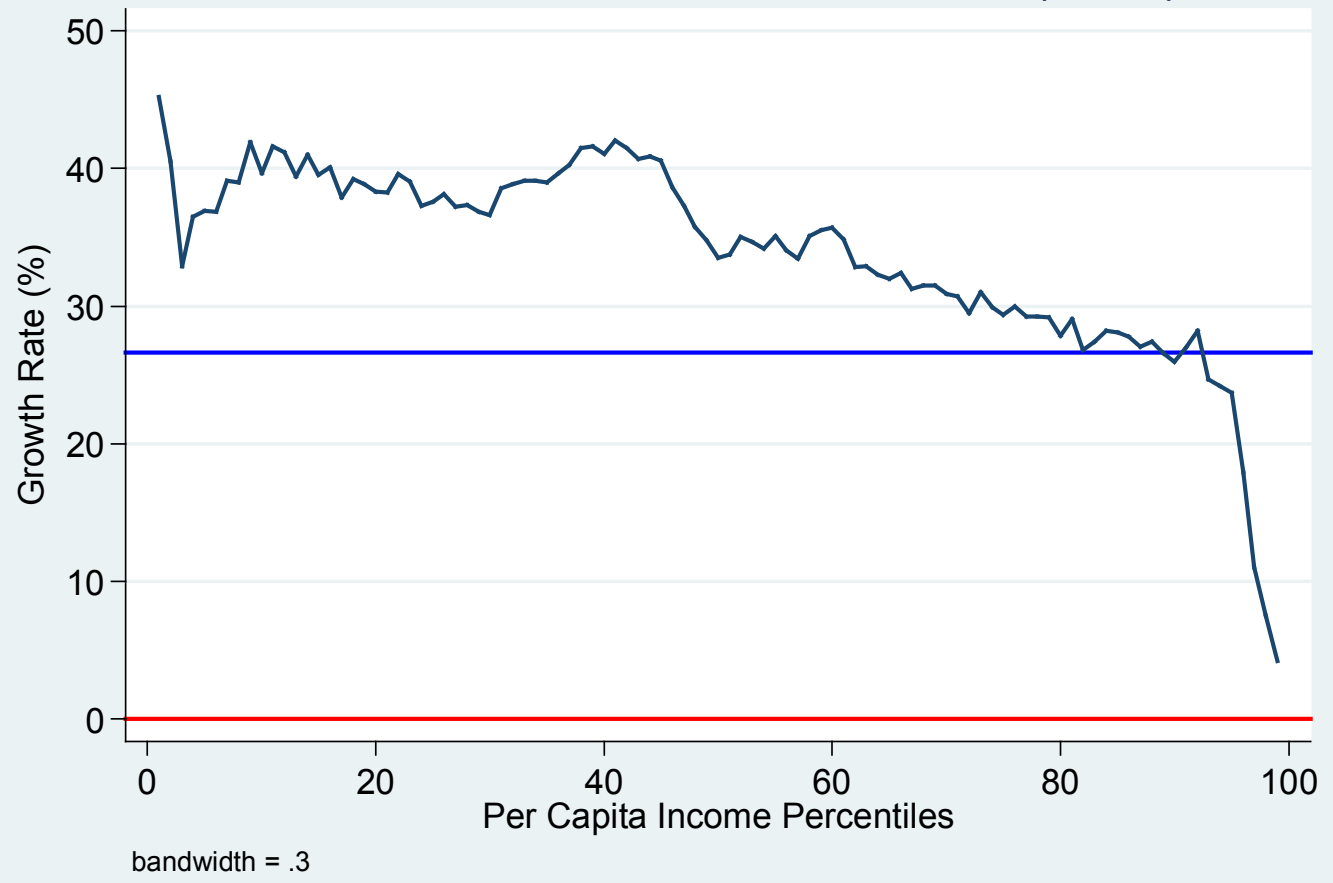

Growth incidence curve: actual and smoothed

Growth rate in the mean income

Zero growth rate 
FiguRE 13
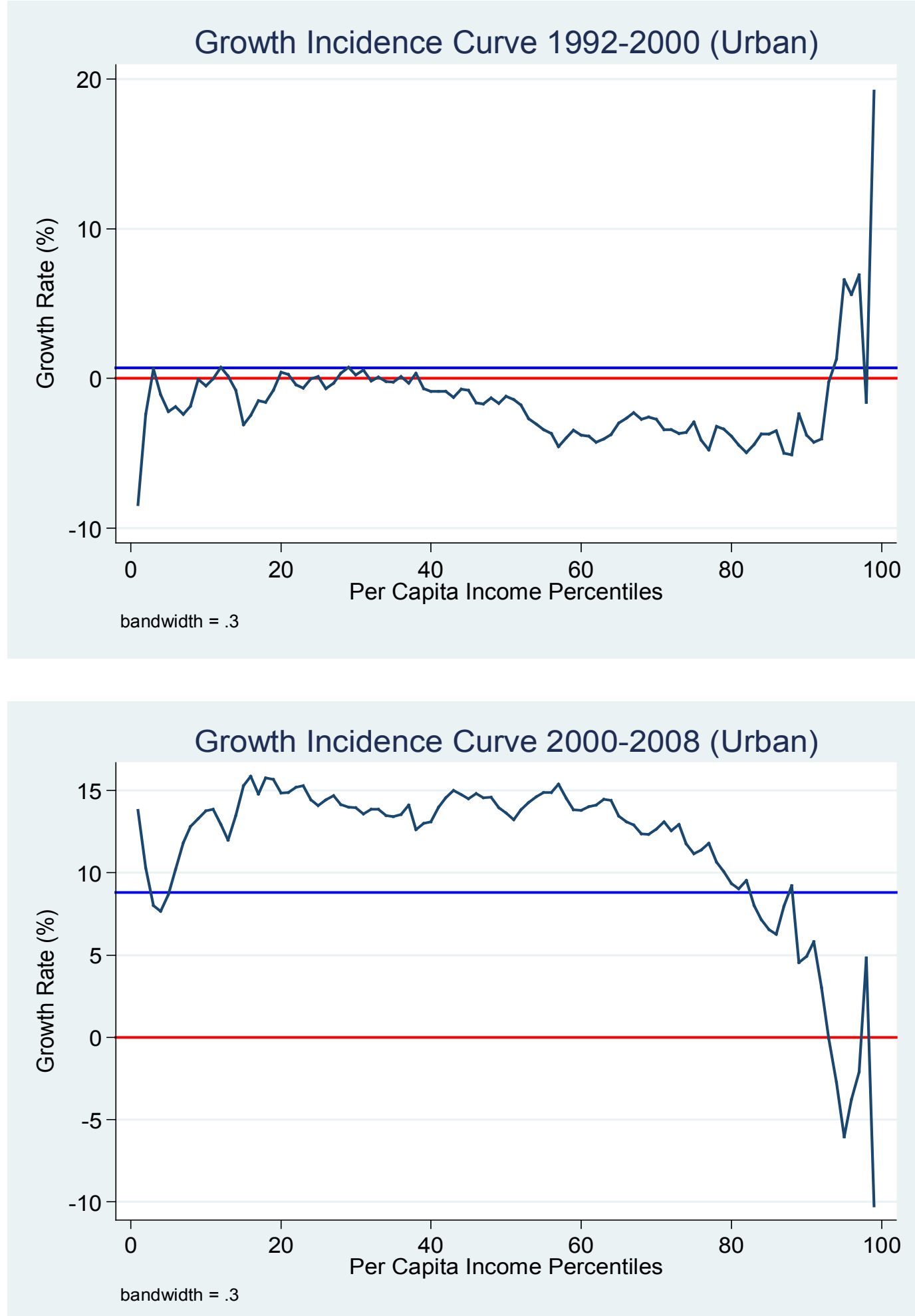

Growth incidence curve: actual and smoothed

Growth rate in the mean income

Zero growth rate 